Supporting Information

\title{
Polypeptide-coated Silica Particles Dispersed in Lyotropic Crystals of the Same Polypeptide
}

Cornelia Rosu, ${ }^{1,2,}$ Sreelatha Balamurugan, ${ }^{2, \S}$ Rafael Cueto, ${ }^{2}$ Amitava Roy ${ }^{3}$ and Paul S. Russo ${ }^{1,2,4^{*}}$

${ }^{1}$ School of Materials Science and Engineering, Georgia Institute of Technology, Atlanta, GA, 30332.

${ }^{2}$ Department of Chemistry and Macromolecular Studies Group, Louisiana State University, Baton Rouge, LA, 70803.

${ }^{3}$ Center for Advanced Microstructures and Devices, CAMD, Louisiana State University, Baton Rouge, LA, 70803.

${ }^{4}$ School of Chemistry and Biochemistry, Georgia Institute of Technology, Atlanta, GA, 30332. ${ }^{\S}$ These authors contributed equally

Section S1 Materials. Stearyl alcohol (octadecanol) (99\%), L-glutamic acid (99\%) tertbutanol (99.5\%), triethylamine (99.5\%), anhydrous dichloromethane (DCM), propargyl amine (98\%), tetraethylorthosilicate (TEOS) (98\%), fluorescein isothiocyanate (FITC), and 3aminopropyltriethoxysilane (APTES), $N, N, N^{\prime}, N^{\prime}, N^{\prime \prime}$-pentamethyldiethylenetriamine (PMDETA) (99\%), $\mathrm{CuBr}$ (99.99\%), tetraethoxysilane (TEOS) (98\%), and sodium azide (purum, p.a, $\geq 99 \%$ ) were purchased from Sigma-Aldrich and used as received.. Triphosgene was obtained from TCI 
America. Dry tetrahydrofuran (THF) was obtained from a PureSolv ${ }^{\mathrm{TM}}$ solvent purification system and Sigma-Aldrich. Cut-off cellulose membrane (12-14 kDa) from Spectrum Laboratories, Inc. USA was used for the dialysis of iron oxide nanoparticles. (3bromopropyl)trichlorosilane was purchased from Gelest. Toluene was obtained from OmniSolv. Sodium citrate dihydrate, Iron (III) chloride hexahydrate $\left(\mathrm{FeCl}_{3} \cdot{ }^{\cdot} 6 \mathrm{H}_{2} \mathrm{O}\right)$ and Iron(II) chloride tetrahydrate $\left(\mathrm{FeCl}_{2} \cdot 4 \mathrm{H}_{2} \mathrm{O}\right)$ were obtained from Fisher Scientific. Absolute anhydrous ethyl alcohol 200 proof ACS/USP grade was obtained from Pharmco-AAPER. Ammonium hydroxide 28-30\% ACS grade was purchased from BDH Aristar. Deionized water $(18 \mathrm{M} \Omega \cdot \mathrm{cm})$ was withdrawn from a Barnstead Nanopure purifier.

\section{Section S2 Experimental Procedures}

\section{Multi-step Grafting to Hybrids}

\section{S2.I.1 Preparation of Magnetite Dispersion, $\mathrm{Fe}_{3} \mathrm{O}_{4}$ (adapted from $\mathrm{Ref}^{1-3}$ )}

A $500 \mathrm{~mL}$ three-neck flask connected to an in-line $\mathrm{N}_{2}$ source, using a long needle and a septum, a mechanical overhead stirrer and a condenser attached to a cooling bath was loaded with $150 \mathrm{~mL}$ of deionized, degassed water (overnight, by bubbling dry $\mathrm{N}_{2}$ ). Two aqueous solutions of iron chlorides were prepared separately as follows: (I) $3.97 \mathrm{~g}$ of $\mathrm{FeCl}_{2} \cdot 4 \mathrm{H}_{2} \mathrm{O}$, (II) $6.33 \mathrm{~g} \mathrm{FeCl}_{3}$ and $4 \mathrm{~mL}$ of deionized, degassed water were added to each vial and injected sequentially into the three-neck flask. The light brown mixture was heated under stirring (300 rpm) at $80^{\circ} \mathrm{C}$. Then $60 \mathrm{~mL}$ of $10 \mathrm{M} \mathrm{NaOH}$ (prepared in degassed deionized water) were injected slowly through a septum over a period of 40 minutes while the temperature was kept at $80^{\circ} \mathrm{C}$. The solution changed color from light to dark brown and finally became the color of black mud. After the addition of the base, temperature was maintained at $80^{\circ} \mathrm{C}$ for another 30 minutes. Then $100 \mathrm{~mL}$ solution of $0.6 \mathrm{M}$ sodium citrate was added and the temperature was increased to $95^{\circ} \mathrm{C}$. 
Heating and stirring continued for 90 minutes. The black slurry, indicative of magnetite formation, was cooled down to the room temperature while stirring continued. The black mud was poured into a large beaker $(1000 \mathrm{~mL})$ containing $400 \mathrm{~mL}$ of acetone. The particles precipitated almost instantaneously. The precipitation step was repeated twice. Particles were collected with a strong Neodymium magnet each time by withdrawing them to the lateral flask's wall surface. In order to collect all particles the dispersion was separated into four or five 200 $\mathrm{mL}$ beakers each containing $\sim 100 \mathrm{~mL}$ of magnetic solution. A volume of $100 \mathrm{~mL}$ and a concentration of $20 \mathrm{mg} \cdot \mathrm{mL}^{-1}$ of magnetite required 3-5 minutes of magnet exposure for complete separation. Finally they were dispersed in water and formed an uniform dispersion. In order to remove the excess reagents (e.g., $\mathrm{NaOH}$, citric acid), magnetite particles were dialyzed over deionized, degassed water by using a 6-8 KDa cutoff membrane made from regenerated cellulose which had been previously boiled in deionized water for 15 minutes. The dialysis took place in a glove bag over a period of 3 days in an inert $\mathrm{N}_{2}$ atmosphere to prevent particle oxidation. The dialysis water (deionized and degassed) was changed every 6 hours initially, and then over a longer period of time until the $\mathrm{pH}$ changed from 13 to 7 . Finally the magnetite was washed twice with fresh deionized degassed water and stored as an aqueous solution $(\sim 150 \mathrm{~mL})$ in an Erlenmeyer flask capped with a glass stopper insulated with Parafilm.

Yield: $4.13 \mathrm{~g}\left(c=275 \mathrm{mg} \cdot \mathrm{mL}^{-1}\right)$.

S2.I.2 Silica Coating of Magnetite Particles by Sol-Gel Method, $\mathrm{Fe}_{3} \mathrm{O}_{4}-\mathrm{SiO}_{2}$ (adapted from Ref. $^{2,4-9}$ )

The protective silica coating of the magnetite particles was accomplished by using the well-known Stöber procedure with some modifications. ${ }^{2,}{ }^{4-9}$ A $250 \mathrm{~mL}$ two-neck flask was loaded with a mixture of $85 \mathrm{~mL}$ absolute ethanol and $22.7 \mathrm{~mL}$ deionized and degassed water. To 
this mixture $20 \mathrm{~mL}$ of magnetite dispersion (1.14 $\mathrm{g}$ of solids) was added and the dispersion was sonicated for 30 minutes. Then the flask was connected to an overhead stirrer and $3 \mathrm{~mL}$ of ammonium hydroxide (28\%) was added. The mixture was stirred vigorously for $15-20$ minutes and the $\mathrm{pH}$ was measured. The optimum $\mathrm{pH}$ value for silica coating is 9 . In a separate vial $1 \mathrm{~mL}$ of TEOS was diluted with $5 \mathrm{~mL}$ of absolute ethanol. The alcoholic solution containing the silanization precursor was injected into the magnetite mixture dropwise, over 30 minutes while the mixture was vigorously stirred $(400-500 \mathrm{rpm})$. The reaction continued for 12 hours. The particles were then washed three times with absolute ethanol and then three times with deionized water using a magnet for separation. Finally they were suspended in water.

Yield: $2.1 \mathrm{~g}\left(c=15.7 \mathrm{mg} \cdot \mathrm{mL}^{-1}\right)$.

NOTE-S1: A thinner silica shell ( 2 $\mathrm{nm})$ can be obtained by following the same procedure but using half of the TEOS amount. For a thicker shell ( 8 nm, etc.,) use the same amount of TEOS as used in the present recipe but in two sequential additions.

\section{S2.I.3 FITC-APTS Adduct ${ }^{10}$}

Fluorescein isothiocyanate $(50 \mathrm{mg}, 0.12 \mathrm{mmol})$ and $10 \mathrm{~mL}$ of absolute ethanol were suspended in a $50 \mathrm{~mL}$ round-bottomed flask capped with a septum. The mixture was magnetically stirred for 30 minutes and 3-aminopropyltriethoxy silane $(0.5 \mathrm{~mL}, 1.2 \mathrm{mmol})$ was injected into the solution through the septum. The reaction proceeded for 18 hours in the dark (to prevent the dye from bleaching).

Yield: assumed 100\% 


\section{S2.I.4 Fluorescent Labeling of Silica-coated Magnetite Particles via Sol-Gel, $\mathrm{Fe}_{3} \mathrm{O}_{4}-\mathrm{SiO}_{2}$ -}

$[\text { FITC-SiO }]^{11}$

Silica-coated magnetite was suspended in a basic ethanol solution (S1) in a $200 \mathrm{~mL}$ twoneck round-bottomed flask connected to an overhead mechanical stirrer. The mixture was sonicated with a probe sonicator for 5 minutes to ensure a good dispersion of the particles. In a separate vial, an alcoholic solution of TEOS (S2) was prepared. This solution and the amount of the fluorescent complex were injected simultaneously into the flask. The reaction was carried out at room temperature, with stirring $(200-300 \mathrm{rpm})$ for 12 hours. The particles were washed three times with absolute ethanol, three times with deionized water and finally suspended in absolute ethanol. A magnet was used to separate particles by immobilization to the side wall of the flask. The amounts of the dye complex and alcoholic solutions are listed in the Table S2.I.-1.

Table S2.I.-1 Sample Code, Amounts of the Magnetic Suspension, Solutions S1 and S2, Amounts of the Dye Adduct and Yields of the Fluorescent Magnetite Particles.

\begin{tabular}{cccccc}
\hline Sample Code & $\begin{array}{c}\text { Magnetic } \\
\text { suspension/g }\end{array}$ & $\begin{array}{c}\text { Solution 1 (S1) } \\
\text { EtOH/water/mL }\end{array}$ & $\begin{array}{c}\text { Solution 2 } \\
(\text { S2.I. }) \\
\text { TEOS/EtOH/mL }\end{array}$ & $\begin{array}{c}\text { Dye } \\
\text { adduct }\end{array}$ & Yield/g \\
\hline $\mathrm{Fe}_{3} \mathrm{O}_{4}-\mathrm{SiO}_{2}$-[FITC-SiO & & \\
\hline
\end{tabular}

S2.I.5 Preparation of Silica-protected Fluorescent Magnetite via Sol-Gel, $\mathrm{Fe}_{3} \mathrm{O}_{4}-\mathrm{SiO}_{2}-[\mathrm{FITC}$ $\left.\mathrm{SiO}_{2}\right]-\mathrm{SiO}_{2}{ }^{11}$

The silica coating performed at this step had the role to prevent dye bleaching and leaking and it was performed on the magnetic particles described in S2.I.4. The procedure followed the same well-known Stöber procedure as described in the previous steps.

Fluorescein isothiocyanate-tagged silica-magnetite, $\mathrm{Fe}_{3} \mathrm{O}_{4}-\mathrm{SiO}_{2}$-[FITC-SiO 2$],(1.34 \mathrm{~g})$ was dispersed in $107 \mathrm{~mL}$ absolute ethanol and $27 \mathrm{~mL}$ deionized water inside a two-neck flask. The mixture was probe sonicated for 5 minutes. The flask was connected to an overhead 
mechanical stirrer and $3.5 \mathrm{~mL}$ ammonium hydroxide (28\%) was added to ensure the basic $\mathrm{pH}$ (9) for condensation. The suspension was stirred (150 rpm) for 15-20 minutes. In a separate vial, a solution consisting of $12 \mathrm{~mL}$ absolute ethanol and $567.5 \mu \mathrm{L}$ TEOS was prepared. This solution was added dropwise to the magnetite mixture using a burette (flow rate $\sim 20 \mu \mathrm{L} \cdot \mathrm{min}^{-1}$.). The reaction continued for 12 hours. Then the particles were washed three times with absolute ethanol, three times with deionized water using a magnet and finally suspended in absolute ethanol.

Yield: $1.56 \mathrm{~g}\left(c=11 \mathrm{mg} \cdot \mathrm{mL}^{-1}\right)$.

S2.I.6 Functionalization of Fluorescent Silica-coated Magnetite Particle Surface with Bromine Groups, $\mathrm{Fe}_{3} \mathrm{O}_{4}-\mathrm{SiO}_{2}-\left[\mathrm{FITC}-\mathrm{SiO}_{2}\right]-\mathrm{SiO}_{2}-\mathrm{Br}$. ${ }^{12-16}$

Silica-protected fluorescent magnetite particles, $\mathrm{Fe}_{3} \mathrm{O}_{4}-\mathrm{SiO}_{2}-\left[\mathrm{FITC}-\mathrm{SiO}_{2}\right]-\mathrm{SiO}_{2},(0.33 \mathrm{~g})$ were suspended twice in dry toluene $(\sim 30 \mathrm{~mL})$ using a magnet. Then they were loaded as a dispersion (50 mL toluene was used) into a three-neck flask immersed in an oil bath and connected to an in-line $\mathrm{N}_{2}$ and an overhead stirrer. To remove water traces, $5 \mathrm{~mL}$ of toluene was collected by distillation using a Dean Stark adaptor and a condenser attached to a cooling bath. The stirring rate was $150 \mathrm{rpm}$. In a separate vial $151 \mu \mathrm{L}$ of (3-bromopropyl)trichlorosilane was mixed with $1 \mathrm{~mL}$ toluene. This mixture was injected in the magnetic suspension dropwise under stirring and $\mathrm{N}_{2}$ bubbling. The reaction continued for 18 hours at $80^{\circ} \mathrm{C}$ and then was cooled down to room temperature. Finally the particles were subjected six times to centrifugation and redispersion in absolute ethanol and stored in the same solvent.

Yield: $0.39 \mathrm{~g}\left(c=7.8 \mathrm{mg} \cdot \mathrm{mL}^{-1}\right)$. 


\section{S2.I.7 Functionalization of Fluorescent Silica-coated Magnetite Particle Surface with Azide Groups, $\mathrm{Fe}_{3} \mathrm{O}_{4}-\mathrm{SiO}_{2}-\left[\mathrm{FITC}-\mathrm{SiO}_{2}\right]-\mathrm{SiO}_{2}-\mathrm{N}_{3}{ }^{12-16}$}

An amount of $0.226 \mathrm{~g}$ of brominated magnetite particles, $\mathrm{Fe}_{3} \mathrm{O}_{4}-\mathrm{SiO}_{2}-\left[\mathrm{FITC}-\mathrm{SiO}_{2}\right]-\mathrm{SiO}_{2}-$ $\mathrm{Br}$ was probe sonicated in $100 \mathrm{~mL}$ dry DMF for 5 minutes and quickly transferred to a threeneck flask connected to an in-line $\mathrm{N}_{2}$ bubbler and an overhead mechanical stirrer. In a separate vial, tetrabutylammonium iodide $(0.038 \mathrm{~g}, 0.001 \mathrm{~mol})$ was added to $2 \mathrm{~mL}$ of dry DMF. This mixture and sodium azide $(1.51 \mathrm{~g}, 0.023 \mathrm{~mol})$ were subsequently introduced into the magnetic suspension under vigorous stirring (300 rpm). The mixture was heated at $80^{\circ} \mathrm{C}$ for 24 hours and then cooled down to room temperature. The particles were washed three times with toluene and three times with DMF; each time, a magnet was used to separate the particles from the rinse. Yield: $0.30 \mathrm{~g}\left(c=2.8 \mathrm{mg} \cdot \mathrm{mL}^{-1}\right)$.

NOTE S2. Another two batches of non-magnetic azide-functionalized silica, $\mathrm{SiO}_{2}-\left[\mathrm{FITC}-\mathrm{SiO}_{2}\right]-$ $\mathrm{SiO}_{2}-\mathrm{N}_{3}$ were prepared using silica particles from our stock

(www.macro.lsu.edu/psrgroup/samples.htm).

\section{S2.I.8 Preparation of $\gamma$-Stearyl-L-glutamate, SLG ${ }^{17}$}

L-glutamic acid (16 g, 0.11M), $t$-butanol (170 mL) and $\gamma$-stearyl alcohol (117.6 g, 0.434 M) were fed into a three-neck flask immersed in an oil bath and connected to a condenser. An inline $\mathrm{N}_{2}$ bubbler was also attached to the flask. The temperature was raised to $40^{\circ} \mathrm{C}$, under magnetic stirring, and then $12 \mathrm{~mL}$ of sulfuric acid was added dropwise, using a dropping funnel. The mixture was further heated at $65^{\circ} \mathrm{C}$ for 45 minutes, by which time a clear solution formed. The oil bath was removed and $12 \mathrm{~mL}(0.084 \mathrm{M})$ of trimethylamine was added dropwise while stirring continued. A white precipitate formed and the stirring was stopped. Ethanol (300 $\mathrm{mL})$, deionized water $(20 \mathrm{~mL})$ and triethylamine $(34 \mathrm{~mL}, 0.242 \mathrm{M})$ were added and a thick white solid 
cake formed upon standing for 30 minutes. The cake was allowed to rest overnight to complete precipitation. The solid was suction filtered and hot methanol $(400 \mathrm{~mL})$ and hot ethyl acetate $(400 \mathrm{~mL})$ were used to rinse the white solid sitting on the filter paper inside the funnel. Then the partially dried solid was transferred into a large beaker charged with $1000 \mathrm{~mL}$ mixture of 1:1 nbutanol and deionized water. The mixture was heated to $95^{\circ} \mathrm{C}$, under magnetic stirring until it became clear (about 60 minutes). After dissolution, the mixture was allowed to cool down to room temperature. White crystals began to form and a complete crystallization was obtained overnight. The crystalline white solid was recovered by filtration and was vacuum dried at ambient temperature for 12 hours.

Yield: $27.15 \mathrm{~g}(63.14 \%)$.

\section{S2.I.9 Preparation of $\gamma$-Stearyl-L-glutamate $N$-carboxyanhydride, SLG-NCA. ${ }^{18}$}

Dry $\gamma$-stearyl-L-glutamate $(5.1 \mathrm{~g}, 0.0125$ molar) and anhydrous THF were added to a three- neck round-bottomed flask equipped with a condenser attached to a cooling bath, a stirring bar, and connected to a nitrogen bubbler in-line to ensure the inert atmosphere and release the pressure formed during reaction. The flask was heated to $50^{\circ} \mathrm{C}$ using an oil bath, and triphosgene $(1.26 \mathrm{~g}, 0.0042$ molar) was added under stirring. After a clear solution formed over 1 hour, the reaction continued for another hour. The mixture was concentrated to $1 / 3$ of its volume and poured into twice its volume of cold, dry $n$-hexane. A white precipitate began to form and the complete crystallization was obtained overnight upon refrigeration. In a glovebag filled with dry $\mathrm{N}_{2}$, the crystals were filtered by suction filtration and washed with cold hexane. The white solid was dissolved in dichloromethane, shaken with sodium carbonate (a small amount $\sim 150 \mathrm{mg}$ ) and filtered through a pad of Celite deposited on cotton. The filtrate was concentrated and cold 
hexane was poured slowly into it. The recrystallization was performed thrice. Finally the white solid was dried in vacuo and freshly used in the next step.

Yield: $3.97-4.24 \mathrm{~g}, 75-80 \%$

NOTE-S3: The dissolution of the NCA in THF during recrystallization steps might require warming the mixture. The flask containing NCA solution should be attached to a bubbler to release the pressure caused by the THF vapors. Preheated water $\left(T \sim 30-35^{\circ} \mathrm{C}\right)$ or a heat gun can be used to warm with caution the mixture with continuous swirling.

NOTE-S4: Triphosgene is a toxic chemical. Therefore, the reaction is conducted in a wellventilated hood and the $\mathrm{HCl} /$ phosgene gas formed during reaction should be passed through an ammonium hydroxide solution for neutralization purposes. This is realized by connecting the bubbler to a flask containing ammonium hydroxide. The triphosgene should be weighed inside the hood.

\section{S2.I.10. Preparation of Alkyne-terminated Poly( $\gamma$-stearyl-L-glutamate), PSLG-Pr}

The alkyne-terminated polypeptides were prepared by ring-opening polymerization of the $\mathrm{N}$-carboxyanhydride of $\gamma$-stearyl-L-glutamate. The reagents used are listed in Table S2.I.-2.

Table S2.I.-2 Reaction Conditions Used in the Synthesis of PSLG-Pr.

\begin{tabular}{|c|c|c|c|c|c|c|c|}
\hline \multirow[t]{2}{*}{ Polypeptide } & \multirow[t]{2}{*}{$\begin{array}{l}\text { Solvent } \\
\mathrm{DCM} / \mathrm{mL}\end{array}$} & \multirow[t]{2}{*}{$\begin{array}{l}\text { Monomer } \\
\text { Concentration } / \%\end{array}$} & \multirow[t]{2}{*}[\mathrm{M}]{$/[\mathrm{I}]$} & \multicolumn{2}{|c|}{ SLG-NCA } & \multicolumn{2}{|c|}{$\begin{array}{l}\text { Propargyl } \\
\text { amine }\end{array}$} \\
\hline & & & & Mass/g & Mol & Mass/g & Mol \\
\hline PSLG-Pr & 50 & 2 & $100: 1$ & 1.0 & 0.002 & 0.001 & 0.0004 \\
\hline
\end{tabular}

The amount of the NCA was weighed inside a glove bag into a $50 \mathrm{~mL}$ round-bottom flask. To this, the solvent, anhydrous dichloromethane, DCM, was added and the flask was capped with a rubber septum. The mixture was swirled until the NCA completely dissolved. Then the initiator, propargyl amine was dissolved in $1 \mathrm{~mL}$ of the solvent inside the glove bag and was injected into 
the NCA solution using a syringe. The flask was immersed in a water bath set at $30^{\circ} \mathrm{C}$ and connected to an in-line nitrogen bubbler to release pressure formed during reaction. The polymerization of NCA was allowed to continue for 72 hour until no gas bubbling was noticed. Purification of the alkyne-polypeptides was performed as follows: the alkyne-PSLG mixture was concentrated to a thick solution by bubbling dry nitrogen and precipitated in acetone $(\sim 75 \mathrm{~mL})$. The so-obtained polypeptide was suction filtered through Whatman filter paper $55 \mathrm{~mm}$ circles, washed with acetone $(\sim 50 \mathrm{~mL})$ on the filter paper and dried in vacuo overnight.

Yield: $0.82 \mathrm{~g}$

NOTE-S5: Another two polymers, alkyne-PSLG, used in this study were prepared using a 10:1 and 300:1 monomer-to-initiator ratios. The data are summarized in Table S2.I.-3.

Table S2.I.-3. Alkyne-PSLG Polymer Code, Monomer-to-initiator Ratios, Theoretical Molecular Weight, Number-average Molecular Weight, Weight-average Molecular Weight, Polydispersity Index and Length of the Synthesized PSLG Polypeptides.

\begin{tabular}{|c|c|c|c|c|c|c|}
\hline Code & {$[\mathbf{M}] /[\mathbf{I}]$} & Theoretical M/kDa & $M_{\mathrm{n}} / \mathrm{kDa}$ & $M_{\mathrm{w}} / \mathrm{kDa}$ & $M_{\mathrm{w}} / M_{\mathrm{n}}$ & $\mathbf{L} / \mathbf{A}$ \\
\hline PSLG-1 & $10: 1$ & 4 & 9.2 & 26 & 2.82 & 102 \\
\hline PSLG-2 & $300: 1$ & 110 & 90 & 107 & 1.18 & 420 \\
\hline
\end{tabular}

\section{S2.I.11Surface Grafting of Alkyne End-terminated PSLG and Onto Azido-fluorescent Silica- coated Magnetite Particles through Huisgen's 1,3-Dipolar Addition}

The reagent amounts used in synthesis are listed in Table S2.I.-4.

Table S2.I.-4 Synthesized Hybrid Name, Amounts of Azido-functionalized Magnetic Silica, Polypeptide, CuBr, PMDETA, Solvent and the Yield of Particles Obtained from Click Reaction. 


\begin{tabular}{lllllll}
\hline Hybrid & $\begin{array}{l}\text { Azide-magnetic } \\
\text { Silica/g }\end{array}$ & Polypeptide/g & CuBr/g & PMDETA/mL & Solvent/mL & Yield/g \\
\hline MGT & 0.230 & 0.6 & 0.091 & 0.26 & 30 & 0.25 \\
\hline
\end{tabular}

Azido-magnetic silica was dispersed in $10 \mathrm{~mL}$ of dry toluene inside a three-neck flask which was connected to a nitrogen line, a condenser connected to a cooling bath and an overhead mechanical stirrer. This suspension was degassed for 10 - 15 minutes. In a separate vial, the alkyne-polypeptide was dissolved in $10 \mathrm{~mL}$ of the reaction solvent (toluene) and was degassed for 10 minutes. In another vial $\mathrm{CuBr}$ was weighed and dissolved in $10 \mathrm{~mL}$ of the toluene. The vial was capped with a rubber septum and the mixture was stirred and degassed for 10 minutes. To the $\mathrm{CuBr}$ mixture, PMDETA was added using a syringe. These degassed solutions of alkyne polypeptide and $\mathrm{CuBr}$ were injected sequentially into the three-neck flask containing the azidofunctionalized magnetite. The flask was immersed in an oil bath and heated to $60^{\circ} \mathrm{C}$ for 1 hour and then to $40^{\circ} \mathrm{C}$ for 24 hours. The reaction mixture was cooled down to the ambient temperature and the particles were separated by a magnet. In order to remove unreacted polypeptide, washings with toluene were performed three times by magnet withdrawing/dispersion. Afterwards the hybrid particles were dispersed in chloroform and extracted with water, a sodium salt solution of EDTA ( $\sim 1 \%$ in water), and again with water to remove the copper. After copper removal the click colloid was washed three times with chloroform. This reaction was repeated twice.

NOTE-S6: Non-magnetic fluorescent PSLG-grafted silica was produced after the abovedescribed procedure and using the PSLG-1 and PSLG-2 polymers obtained in S2.1.10 and listed in Table S.2.1-3. Fluorescent silica beads $\left(R_{\mathrm{DLS}}=103 \pm 2 \mathrm{~nm}\right)$ were used from our stock (see www.macro.lsu.edu/psrgroup/samples.htm). 
The stock fluorescent silica was prepared following the same steps as for the fluorescent core, except they do not have the magnetite core.

NOTE S7: During the synthesis the exposure of the magnetic reaction mixture to the magnetic field from the hotplate was shielded by two $\mu$-metal plates.

NOTE-S8: The same procedure was followed to prepare GT1 and GT2 particles.

\section{One-pot Grafting From Hybrid}

\section{S2.II.1 Preparation of $\mathrm{Fe}_{3} \mathrm{O}_{4}$ nanoparticle: ${ }^{1}$}

$\mathrm{Fe}_{3} \mathrm{O}_{4}$ nanoparticles were prepared by the addition of ammonium hydroxide to an aqueous solution of $\mathrm{FeCl}_{2}$ and $\mathrm{FeCl}_{3}$, in the ratio of $1: 2 . \mathrm{FeCl}_{2} \cdot 4 \mathrm{H}_{2} \mathrm{O}(2.58 \mathrm{~g})$ and $\mathrm{FeCl}_{3} \cdot 6 \mathrm{H}_{2} \mathrm{O}(7.05 \mathrm{~g})$ were weighed and dissolved in $120 \mathrm{~mL}$ of degassed deionized water in a $500 \mathrm{~mL}$ 3-neck round-bottom flask equipped with a nitrogen inlet, mechanical stirring and water condenser. The solution was stirred and heated to $80^{\circ} \mathrm{C}$. $\mathrm{NH}_{4} \mathrm{OH}(15 \mathrm{~mL})$ was added to this solution using a syringe and the heating was continued for 30 minutes. Next, $50 \mathrm{~mL}$ of $0.3 \mathrm{M}$ trisodium citrate solution was added and the temperature was raised to $90^{\circ} \mathrm{C}$. Stirring and heating were continued for another 90 minutes. The solution was then cooled to room temperature and added to acetone $(\sim 1 \mathrm{~L})$ to precipitate the iron oxide particles. This was repeated once more and the particles were collected using a strong magnet. They were then washed with degassed deionized water. The particles were then dialyzed using 12$14 \mathrm{kDa}$ molecular weight cutoff membrane against degassed deionized water for 2 days (changing the water 5 times).

\section{S2.II.2. Silica coating of iron oxide magnetic nanoparticle $\left(\mathrm{Fe}_{3} \mathrm{O}_{4}-\mathrm{SiO}_{2}\right){ }^{8,}$}

Dialyzed magnetic particles in water $(5 \mathrm{~g}$ of $3.2 \mathrm{wt} / \mathrm{v} \%$ solution) were weighed into a 500 $\mathrm{mL}$ three-neck round-bottomed flask, equipped with a nitrogen inlet and mechanical stirrer. Deionized water $(40 \mathrm{~mL})$ and ethanol $(160 \mathrm{~mL})$ were added to this solution under vigorous stirring. 
To this stirred solution, $0.5 \mathrm{~mL}$ of aqueous ammonium hydroxide (30 wt $\%$ ) and $0.5 \mathrm{~mL}$ of TEOS were added. The stirring was continued for 24 hours, resulting in the formation of $\mathrm{Fe}_{3} \mathrm{O}_{4}-\mathrm{SiO}_{2}$ particles in the solution. This solution was then used for the preparation of $\mathrm{Fe}_{3} \mathrm{O}_{4}-\mathrm{SiO}_{2}$-FITC.

\section{S2.II.3. Preparation of $N$-1-(3-triethoxysilylpropyl)- $N$-fluoresceyl thiourea (FITC-APTES) ${ }^{11}$}

APTES $(0.19 \mathrm{~g})$ was added to a solution of FITC $(37 \mathrm{mg})$ in ethanol $(10 \mathrm{~mL})$ under inert conditions and stirred for 12 hours to produce FITC-APTES adduct. This solution was later used for fluorescent labeling.

\section{S2.II.4. Preparation of $\mathrm{Fe}_{3} \mathrm{O}_{4-}-\mathrm{SiO}_{2}-\left[\mathrm{FITC}-\mathrm{SiO}_{2}\right]-\mathrm{NH}_{2}{ }^{11,20}$}

TEOS $(0.5 \mathrm{~mL})$ was mixed with the FITC-APTES reaction mixture and added to the stirring solution of $\mathrm{Fe}_{3} \mathrm{O}_{4}-\mathrm{SiO}_{2}$ and the stirring was continued for another 48 hours to obtain $\mathrm{Fe}_{3} \mathrm{O}_{4}-\mathrm{SiO}_{2}-$ FITC. To this preparation, $0.5 \mathrm{~mL}$ of TEOS was added and the reaction was allowed to stir for 48 hours to get $\mathrm{Fe}_{3} \mathrm{O}_{4}-\mathrm{SiO}_{2}$-[FITC-SiO$\left.{ }_{2}\right]$. APTES $(4 \mathrm{~mL})$ was added to this solution and stirred for another 48 hours to obtain $\mathrm{Fe}_{3} \mathrm{O}_{4}-\mathrm{SiO}_{2}-\left[\mathrm{FITC}-\mathrm{SiO}_{2}\right]-\mathrm{NH}_{2}$. The particles were collected by a strong magnet and washed with ethanol three times to remove the unreacted reagents. The particles in ethanol were separated using a magnet and washed four times with DCM.

S2.II.5. Synthesis of $\gamma$-stearyl-a,L-glutamate (SLG). SLG was synthesized using a reported procedure. See S2.I.8.

\section{S2.II.6. Preparation of $\gamma$-stearyl-a,L-glutamate $N$-carboxyanhydride (SLG-NCA). This} monomer was prepared using a reported procedure. See S.2.I.9.

S2.II.7. Preparation of $\mathrm{Fe}_{3} \mathrm{O}_{4}-\mathrm{SiO}_{2}-\left[\mathrm{FITC}-\mathrm{SiO}_{2}\right]-\mathrm{PSLG}-1, \mathrm{MGF}-1$. This sample was prepared using the ring-opening polymerization of the SLG-NCA, initiated by the amino groups of the $\mathrm{Fe}_{3} \mathrm{O}_{4}$ $\mathrm{SiO}_{2}$-[FITC-SiO $\left.{ }_{2}\right]-\mathrm{NH}_{2}$ particles. These particles $(1 \mathrm{~g}$, in $15 \mathrm{~mL} \mathrm{DCM})$ were added to a flask connected to an in-line nitrogen bubbler, and equipped with a mechanical stirrer. This solution was 
degassed for 15 minutes. SLG-NCA, $1.63 \mathrm{~g}$, was weighed in another flask and $15 \mathrm{~mL}$ of anhydrous DCM was added under inert gas. The solution was stirred and warmed using a heat gun until the SLG-NCA completely dissolved in DCM. This solution was taken in a syringe and injected into the vigorously stirred solution of $\mathrm{Fe}_{3} \mathrm{O}_{4}-\mathrm{SiO}_{2}-\left[\mathrm{FITC}-\mathrm{SiO}_{2}\right]-\mathrm{NH}_{2}$. The final volume of the solution was $25 \mathrm{~mL}$, as some of the solvent was lost during purging and heating. The mixture was stirred at room temperature for three days. The particles were thoroughly washed 4 times with DCM.

Two weight ratios of amine-functionalized particle and SLG-NCA monomer, 1:1.63 (1g of $\mathrm{Fe}_{3} \mathrm{O}_{4^{-}}$ $\mathrm{SiO}_{2}$-FITC- $\mathrm{SiO}_{2}-\mathrm{NH}_{2}$ initiator particle with $0.153 \mathrm{~mol} \mathrm{~L}^{-1}$ of SLG-NCA monomer) and 1:12 (1g of $\mathrm{Fe}_{3} \mathrm{O}_{4}-\mathrm{SiO}_{2}$-FITC- $\mathrm{SiO}_{2}-\mathrm{NH}_{2}$ initiator particle with $0.602 \mathrm{~mol} \mathrm{~L}^{-1}$ of SLG-NCA monomer ) were used to synthesize $\mathrm{Fe}_{3} \mathrm{O}_{4}-\mathrm{SiO}_{2}$-[FITC-SiO 2 -PSLG-1 (MGF1) and $\mathrm{Fe}_{3} \mathrm{O}_{4}-\mathrm{SiO}_{2}$-[FITC-SiO 2$]-P S L G-2$ (MGF2) (Scheme 1). (MGF stands for Magnetic Grafted From). MGF-1 particles were used for all the characterization studies.

S2.II.8. Preparation of $\mathrm{Fe}_{3} \mathrm{O}_{4}-\mathrm{SiO}_{2}-\left[\mathrm{FITC}-\mathrm{SiO}_{2}\right]-\mathrm{PSLG}-2, \mathrm{MGF}-2$. A second batch of grafting from particles was prepared using the same procedure as for MGF-1 particles (the monomer:particle initiator ratio (wt:wt) was 12:1).

\section{Section S3. Supporting graphs and charts}




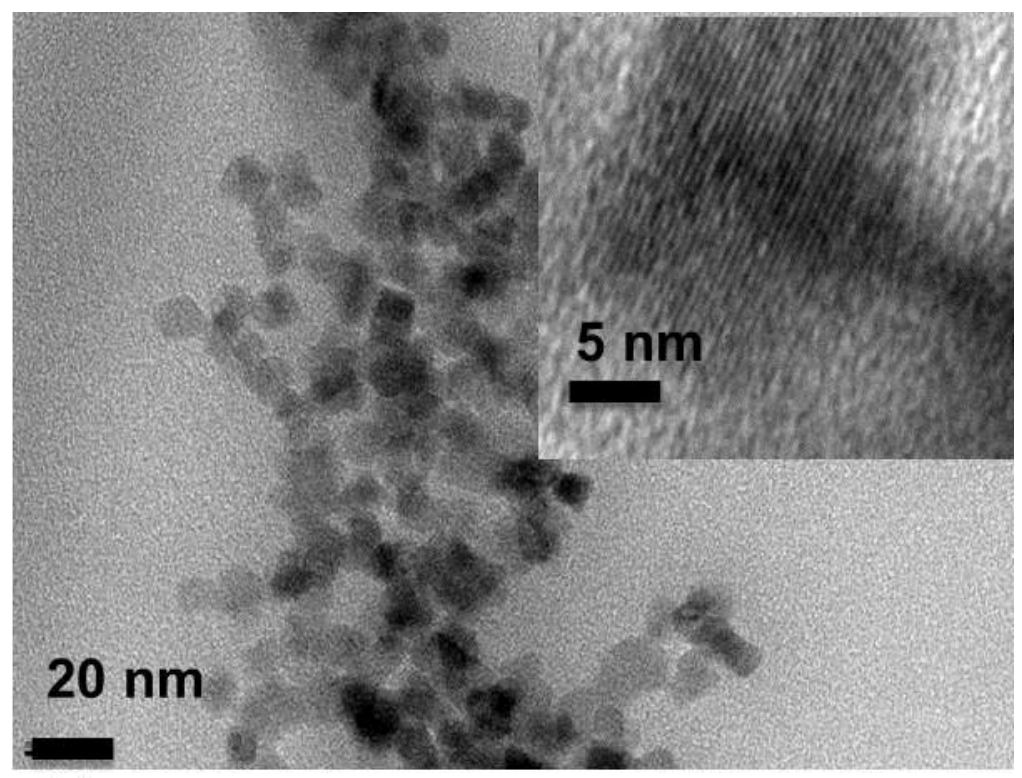

Figure S3.1. HRTEM of magnetite core and its diffraction lattice (inset).

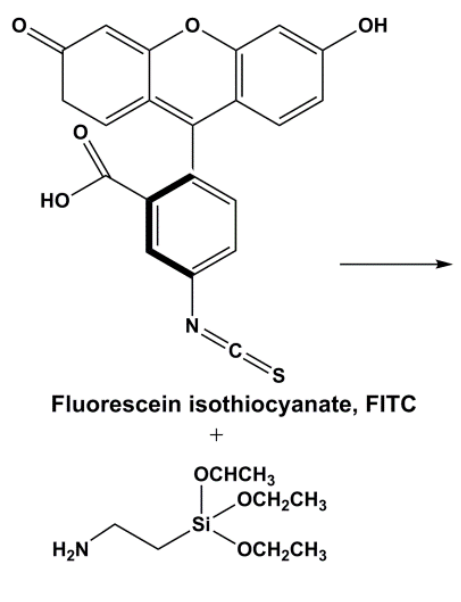

3-Aminopropyltriethoxysilane, APTES

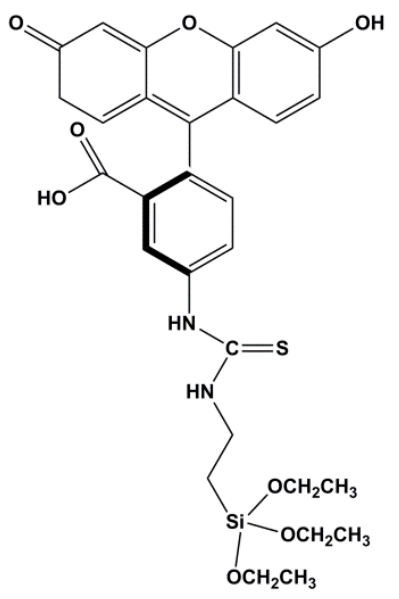

FITC-APTES molecule

Figure S3.2. The chemical structure of the FITC-APTES adduct. 


\section{Grafting to}

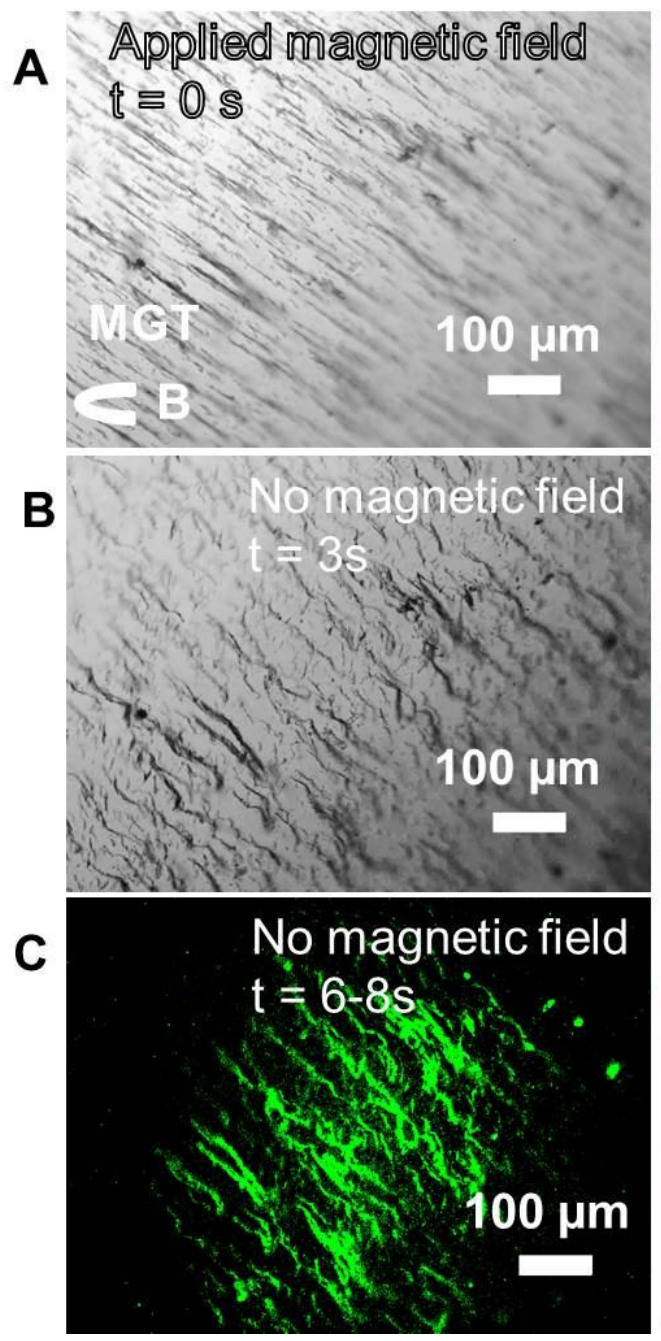

Grafting from
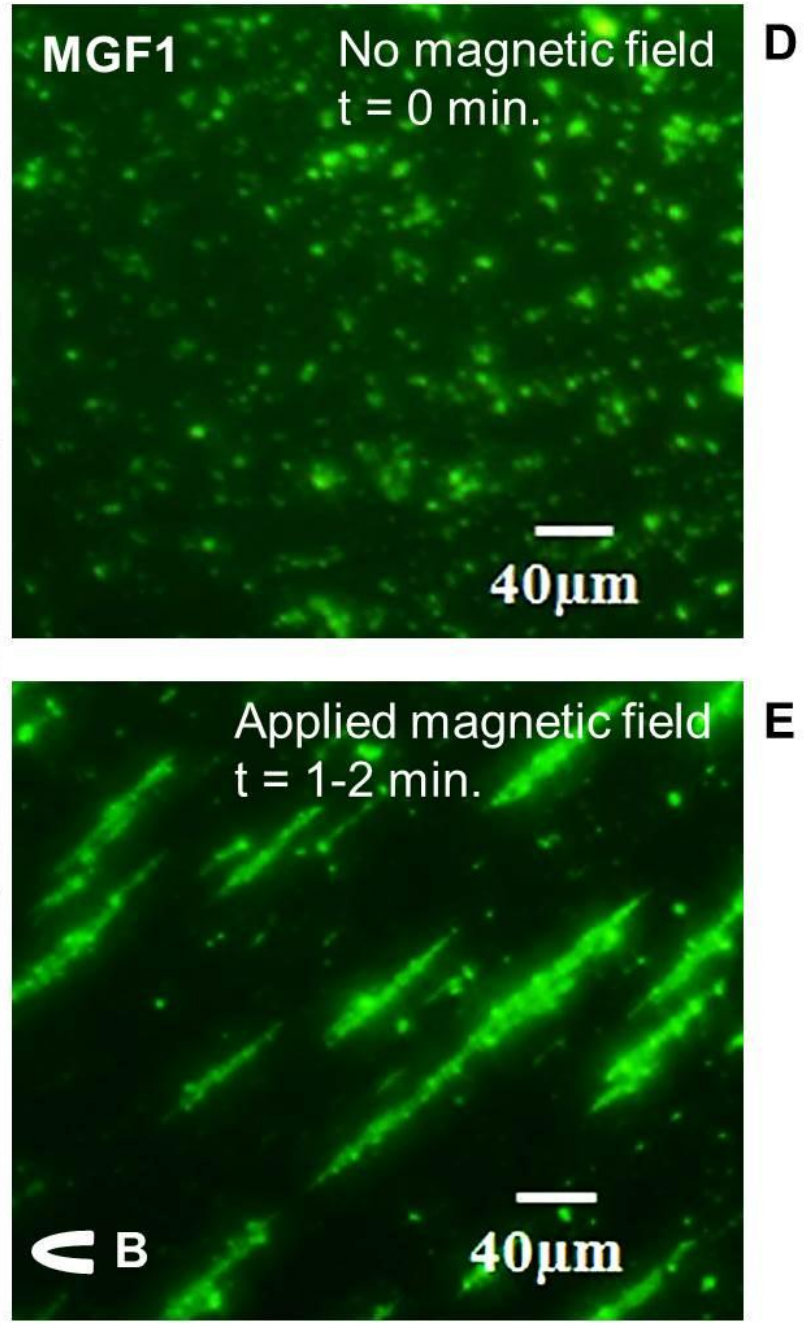

Figure S3.3. Magnetic behavior: MGT (chains aligned in magnetic field, (A), the quick response of the chains (undulating appearance) once the magnetic field was removed, (B), epi-fluorescence image of B, (C) and MGF1 (epi-fluorescence image of MGF1 particles before (D) and after (E) exposure to magnetic field (particle chaining). The magnetic field was provided by a permanent magnet $(0.125 \mathrm{mT})$. 
XPS: The functionalization of the silica-protected magnetite surface $\left(\mathrm{Fe}_{3} \mathrm{O}_{4}-\mathrm{SiO} 2-\left[\mathrm{FITC}-\mathrm{SiO}_{2}\right]-\right.$ $\mathrm{SiO}_{2}$ ) with bromine groups was evident from the high-resolution spectrum of brominefunctionalized particles. Figure S3.4A shows the specific peaks corresponding to $\mathrm{Br} 3 \mathrm{~d}$ at $68 \mathrm{eV}$ and $\mathrm{Br} 3 \mathrm{p}$ at $181.5 \mathrm{eV}$ as well as other elements present on the particle surface. Conversion of bromine moieties to azide groups was evidenced by the disappearance of the bromine peaks and the appearance of the azide N1s centered at $400 \mathrm{eV}$ (Figure S3.4B). A noticeable decrease in the C1s signal was also observed because the replacement of the bromine moieties with the bulky azide can hinder the carbon situated on the particle surface.

Grafting to

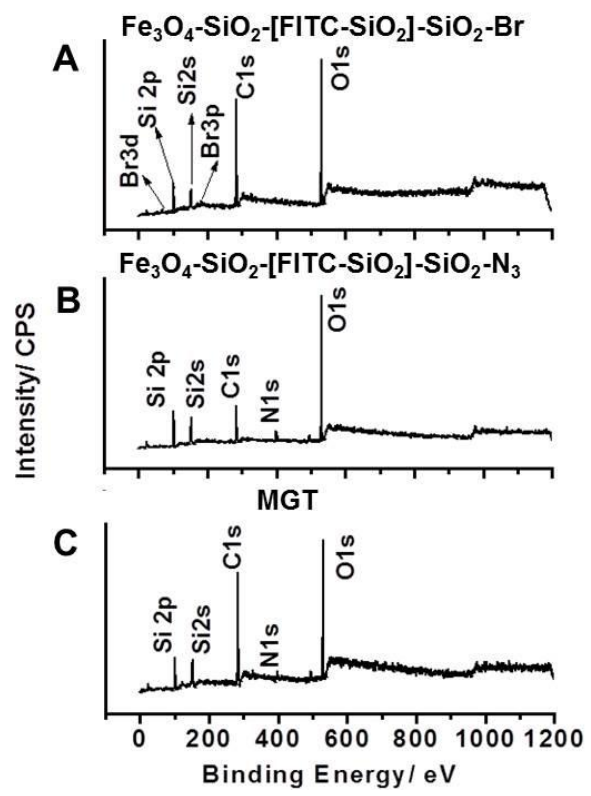

Grafting from

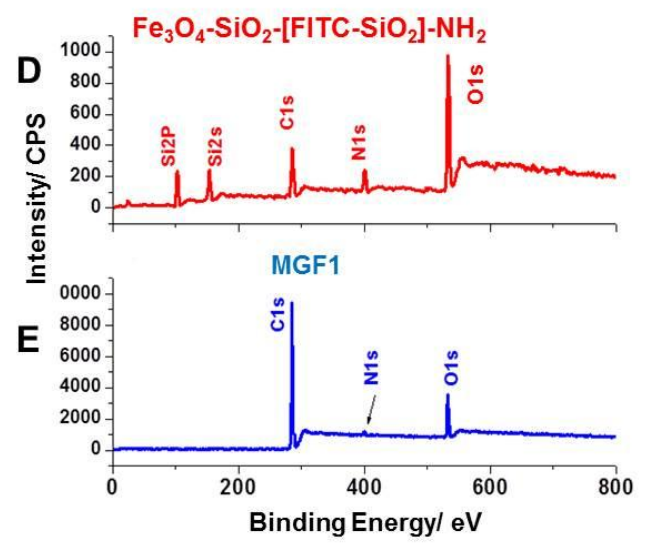

Figure S3.4. XPS survey spectra of: $\mathrm{Fe}_{3} \mathrm{O}_{4}-\mathrm{SiO}_{2}-\left[\mathrm{FITC}-\mathrm{SiO}_{2}\right]-\mathrm{SiO}_{2}-\mathrm{Br}(\mathrm{A}), \mathrm{Fe}_{3} \mathrm{O}_{4}-\mathrm{SiO}_{2}-$ [FITC-SiO$\left.{ }_{2}\right]-\mathrm{SiO}_{2}-\mathrm{N}_{3}(\mathrm{~B}), \mathrm{MGT}(\mathrm{C}), \mathrm{Fe}_{3} \mathrm{O}_{4}-\mathrm{SiO}_{2}-\left[\mathrm{FITC}-\mathrm{SiO}_{2}\right]-\mathrm{NH}_{2}$ (D) and MGF1 (E).

N1s high-resolution spectrum of azide-functionalized particles (Figure S3.5B) provided more insight into their functional group internal structure. The bonds from the azide groups were reflected in the N1s double peaks at 400 and $402.8 \mathrm{eV} .{ }^{21-22}$ The electron deficiency of the 
triazole's middle nitrogen can be seen by the less intense peak at $402.8 \mathrm{eV} .{ }^{22}$ The immobilization of polypeptide on the particle surface through click chemistry was reflected in the XPS survey of the click hybrid (Figure S3.5C) where a decrease in the N1s signal was observed. The contributions to the N1s signal recorded for the click hybrid, MGT, are made by the nitrogen from the polypeptide backbone and possible unreacted azide groups. This is suggested by a split in the high-resolution survey of the N1s signal from the MGT hybrid (Figure S3.7C) that matches the peaks from pristine polypeptide (Figure S3.7B) and azide-functionalized core (Figure S3.7A). The polypeptide folds into a stiff rodlike structure. This conformation might hinder sensing the nitrogen from the polymer backbone. The presence at low intensity of azide N1s in MGT's XPS-survey also suggests a low grafting density of the PSLG chains on the particle surface. The increase of the C1s signal for the PSLG-click magnetic particle (Figure S3.4C) when compared with the signal for the same element recorded for azide-functionalized magnetic silica (Figure S3.4B) indicated the attachment of the polypeptide onto the particle surface.

Figure S3.4E shows the XPS survey spectrum of MGF1 particles, the result of the grafting from method. Compared to the amine-functionalized particles (Figure S3.4D), the polypeptide-grafted particles show a significant increase in the $\mathrm{C}$ 1s peak. The increase in the $\mathrm{C}$ 1s peak intensity is attributed to the growth of polypeptides with long alkyl chains. Surprisingly, we observed a very low signal for the N1s of the MGF1 particles when compared to $\mathrm{Fe}_{3} \mathrm{O}_{4^{-}}$ $\mathrm{SiO}_{2}$-[FITC- $\left.\mathrm{SiO}_{2}\right]-\mathrm{NH}_{2}$ particles. The particles were scanned three times to confirm the result. The reason for the weak signal may be due to the high grafting density. The stretched polypeptide on the particle's surface is crowded with long alkyl chains, which may have masked the polypeptide backbone. The absence of $\mathrm{Fe}$ and Si peaks in Figure S3.4E is due to the fact that 
the silica-coated magnetic particles are densely covered with PSLG chains, and the sensitivity of the XPS analysis decreases exponentially with surface thickness.

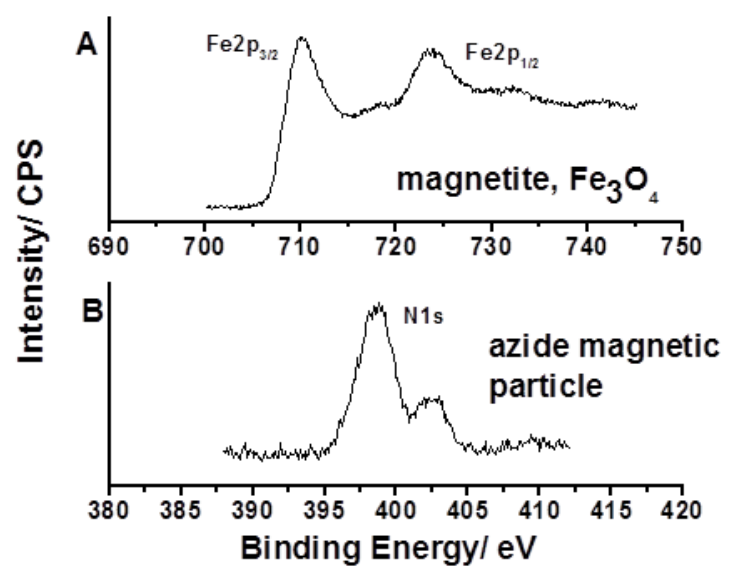

Figure S3.5. High-resolution spectrum of $\mathrm{Fe} 2 \mathrm{p}_{3 / 2}$ and $\mathrm{Fe} 2 \mathrm{p}_{1 / 2}(\mathrm{~A})$ and $\mathrm{N} 1 \mathrm{~s}$ of azide-functionalized particle (B).

The valence of the $\mathrm{Fe}$ ions can be determined from $2 \mathrm{p}$ core-level spectra. ${ }^{23}$ The spectrum displayed in Figure S3.5A shows the bonding energy of $\mathrm{Fe} 2 \mathrm{p}_{3 / 2}$ centered at $710 \mathrm{eV}$ and $\mathrm{Fe} 2 \mathrm{p}_{1 / 2}$ at $723.8 \mathrm{eV}$. It is known that $\mathrm{Fe}$ ions from magnetite bind with carboxylate groups belonging to protective acids. ${ }^{24}$ This linkage is reflected in an XPS survey spectrum by the presence of the C1s peak at $286.7 \mathrm{eV}$ (Figure S3.6A, magnetite). The C-C bonds from the citric acid's alkyl chain also contribute to the occurrence of this signal. 

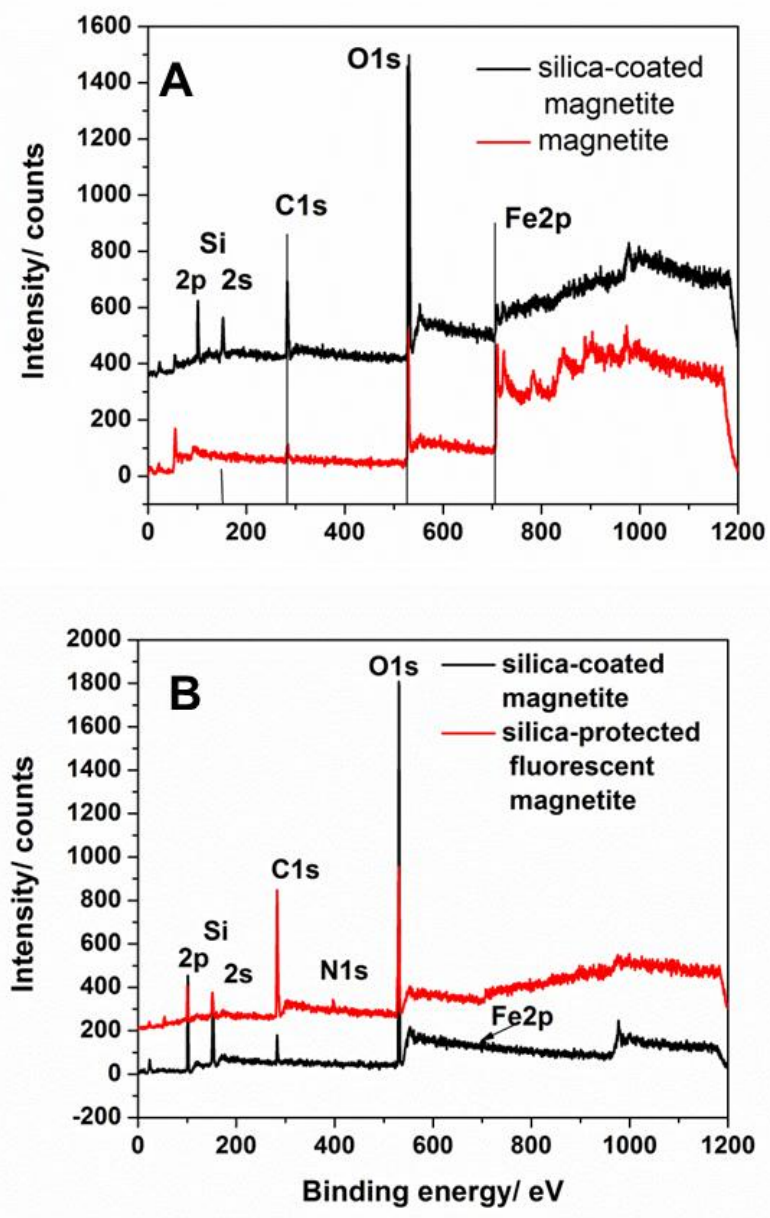

Figure S3.6. Comparative XPS-survey of magnetite (red) and silica-coated magnetite (black), (A). The black curve has a +350 offset. Comparative XPSsurvey of silica-coated magnetite (black) and silica-protected fluorescent magnetite (red), (B). The red curve has a +200 offset. Lines were drawn to guide the eye.

The peak for free acid was not observed in the case of silica-coated (Figure S3.6A) magnetite. XPS confirmed the successful coating of magnetite with silica and was reflected by the specific peaks Si2s $(152.4 \mathrm{eV})$ and Si2p (104.5 eV) (Figure S3.6A). ${ }^{25}$ The covalent fluorescent labeling 
of silica-coated magnetite with the FITC-APTES complex was confirmed by the N1s $(396.5 \mathrm{eV})$ signal and the increased C1s signal (286.7 eV) (Figure S3.6B).
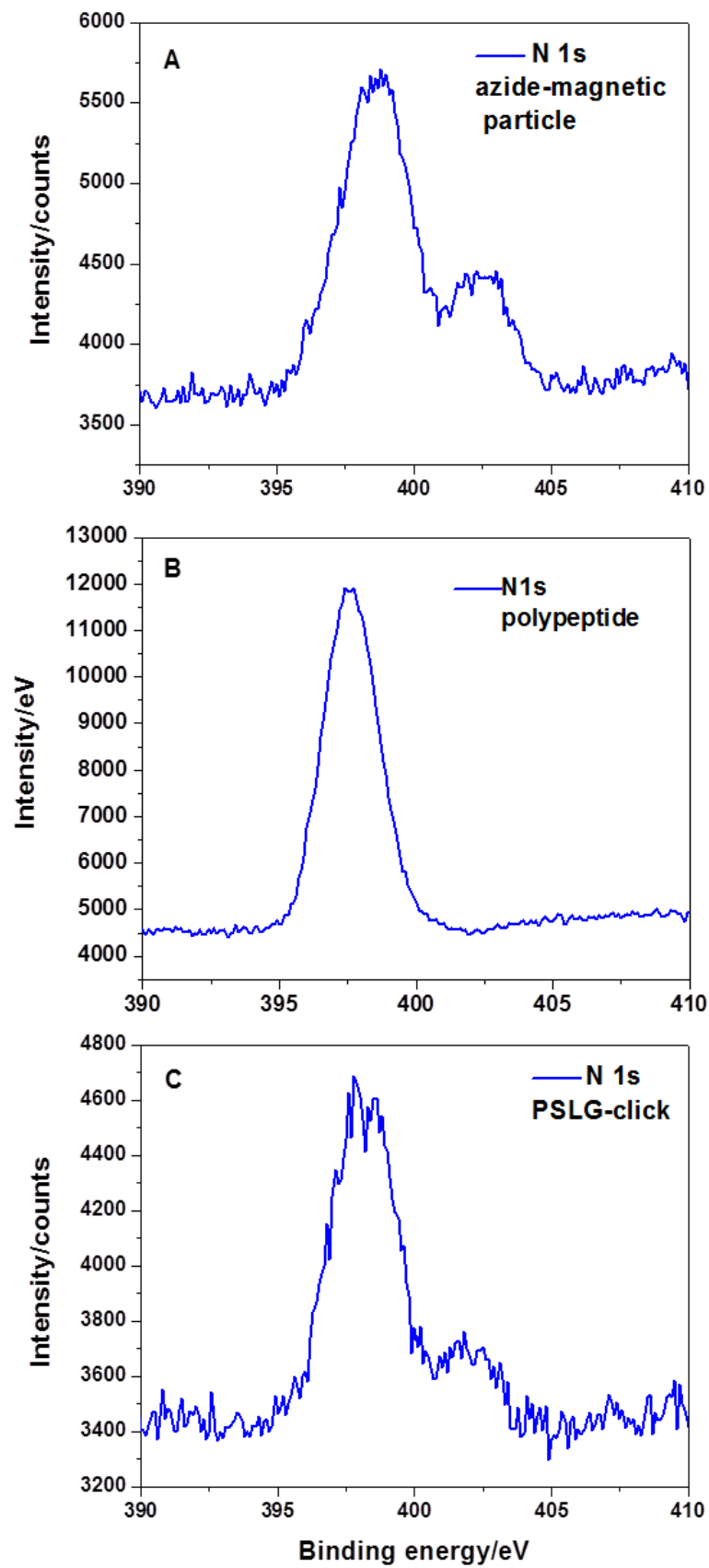

Figure S3.7 Comparative high-resolution N1s XPS-survey of (A) azidemagnetic particle, (B) polypeptide and (C) PSLG-click hybrid. 
FTIR: After preparation, the magnetite colloid had a layer of citrate ions on the surface to retard oxidation and to ensure good dissolution in aqueous solution. The presence of citrate ions was evidenced by FTIR (Figure S3.8 inset): the specific band corresponding to $\mathrm{C}=\mathrm{O}$ can be seen at $1628 \mathrm{~cm}^{-1}$ and the broad $\mathrm{OH}$ signal is visible at $\sim 3500 \mathrm{~cm}^{-1}$. The magnetite specific $\mathrm{Fe}-\mathrm{O}-\mathrm{Fe}$ stretch is reflected in the IR spectrum by the peak centered at $571 \mathrm{~cm}^{-1}$. The ratio between the specific band for silica $(\mathrm{Si}-\mathrm{O}-\mathrm{Si})$ centered at $1086 \mathrm{~cm}^{-1}$ and iron $(\mathrm{Fe}-\mathrm{O}-\mathrm{Fe}$, $571 \mathrm{~cm}^{-1}$ ) indicates the presence of a thin silica layer on the surface.

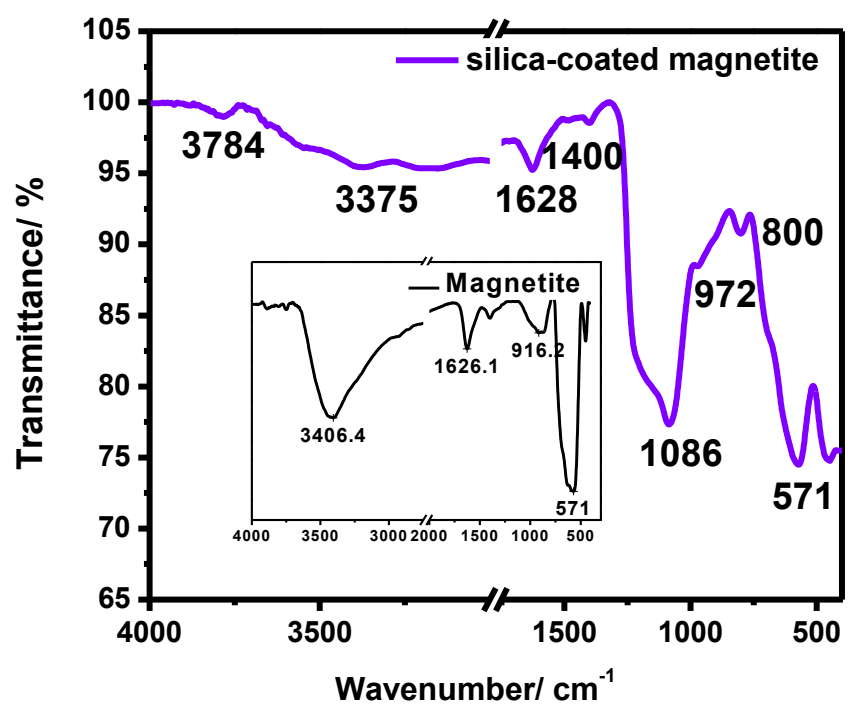

Figure S3.8. FTIR spectra of silica-coated magnetite, $\mathrm{Fe}_{3} \mathrm{O}_{4}-\mathrm{SiO}_{2}$ and magnetite, $\mathrm{Fe}_{3} \mathrm{O}_{4}$ (inset). 


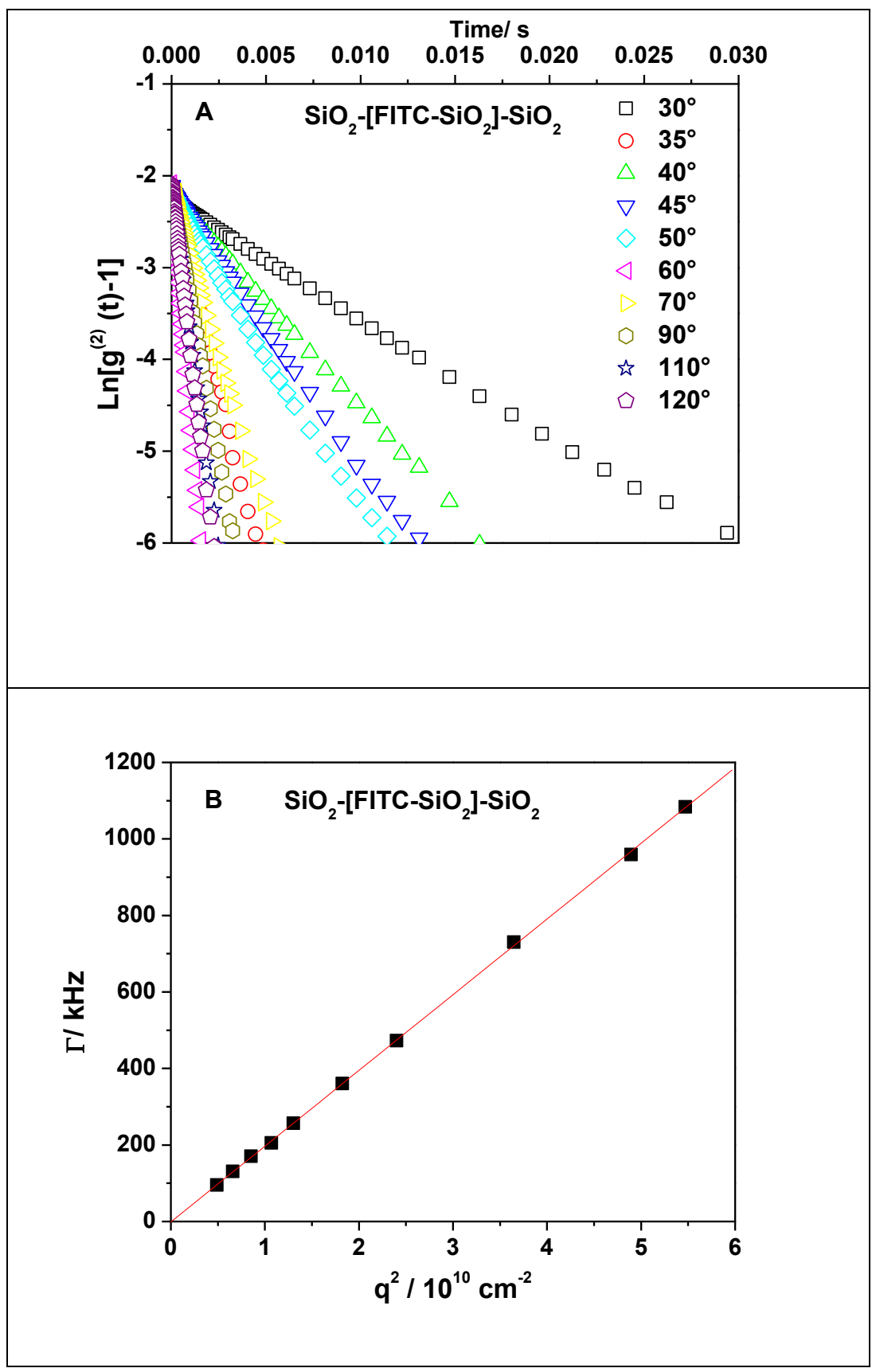




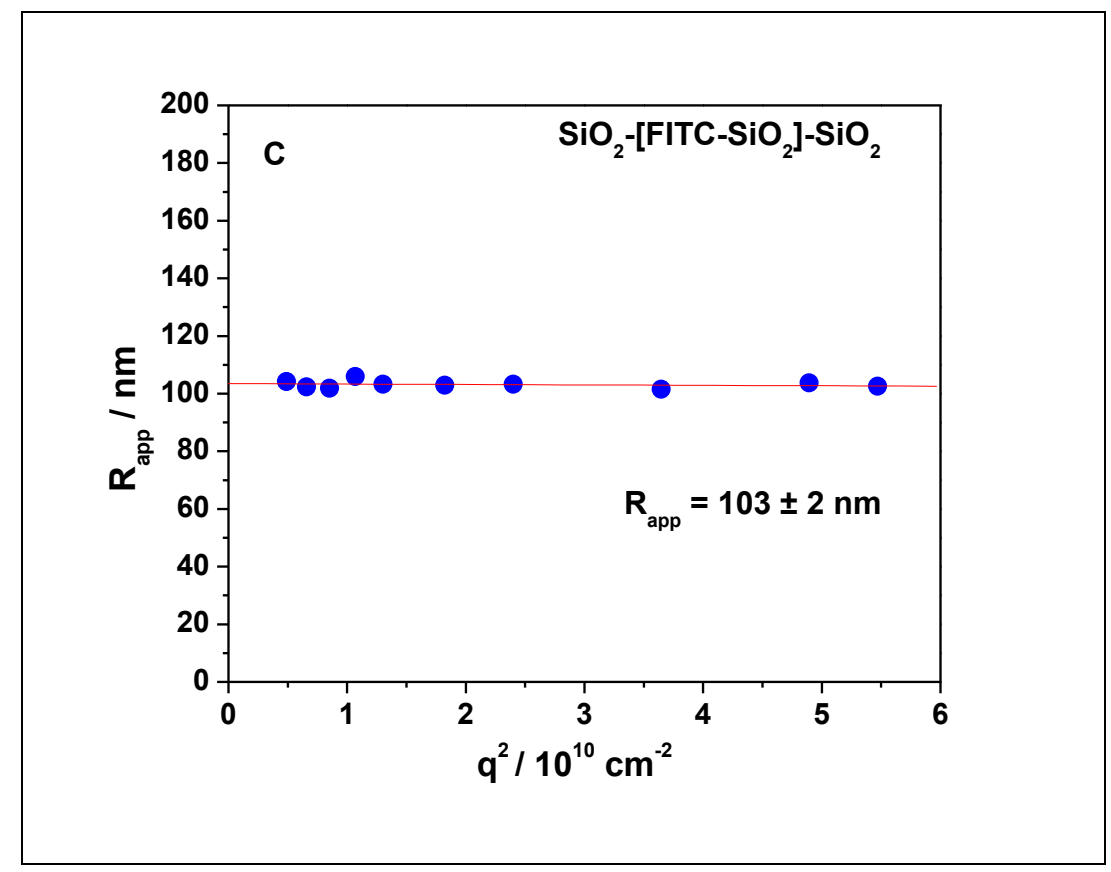

Figure S3.9. DLS data for the silica fluorescent core used in the preparation of the PSLGc-1 and PSLGc-2 hybrids: (A) the correlation function in semilogarithmic form recorded at 10 scattering angles; (B) the decay rate, $\Gamma$ and (C) apparent radius, $R_{\text {app }}$ versus squared vector magnitude, $q^{2}$. Samples were measured in ethanol at $25^{\circ} \mathrm{C}$. Run time was $200 \mathrm{~s}$. Each point is an average of five measurements. As seen in Figure $\mathrm{C}$ the radius does not depend on the scattering angle, suggesting monodisperse particles. 


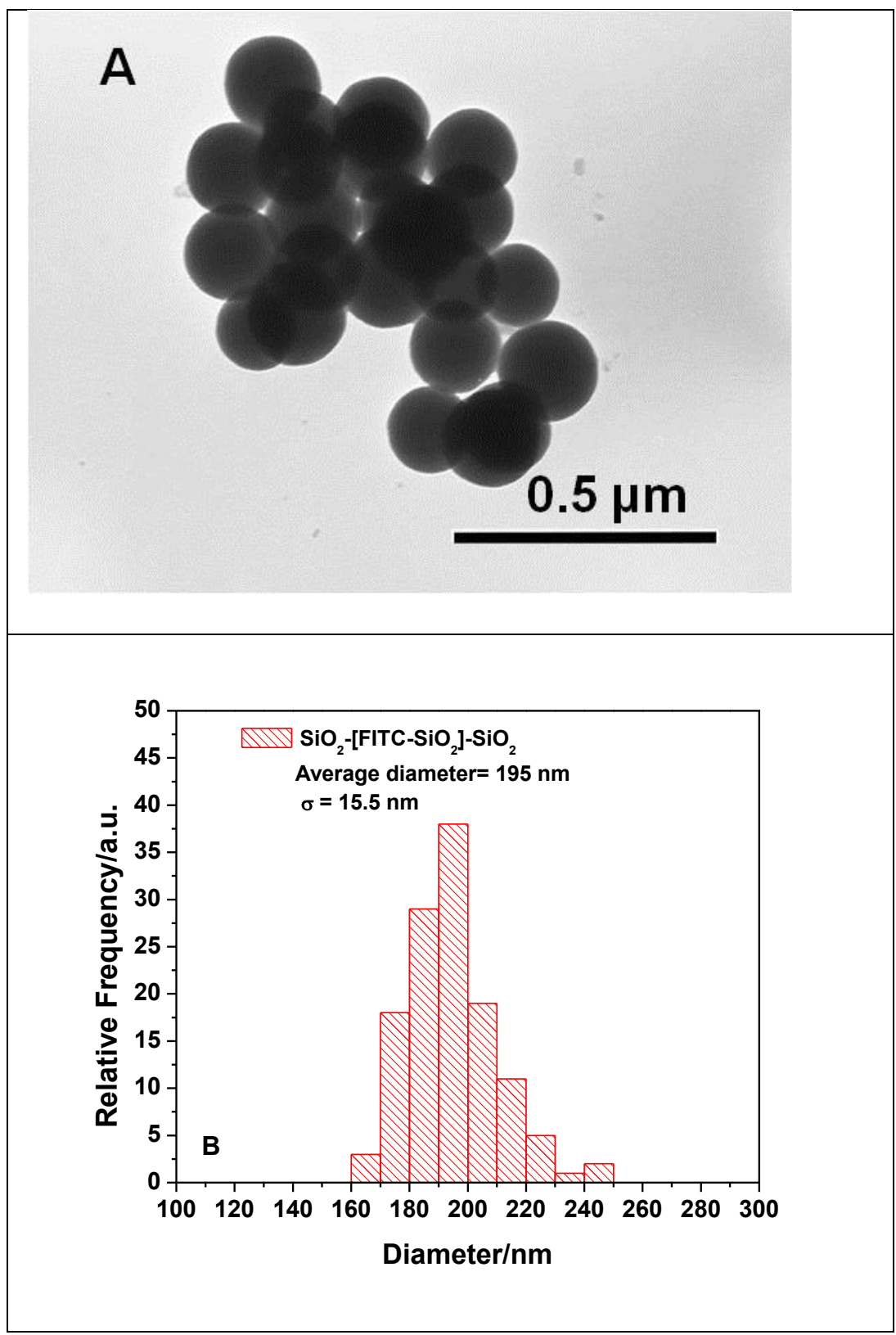

Figure S3.10. TEM image of (A) the silica fluorescent cores used in the GT1 and GT2 hybrids preparation and (B) the histogram showing the size distribution. In the legend, sigma symbol, $\sigma$, is the standard deviation. 


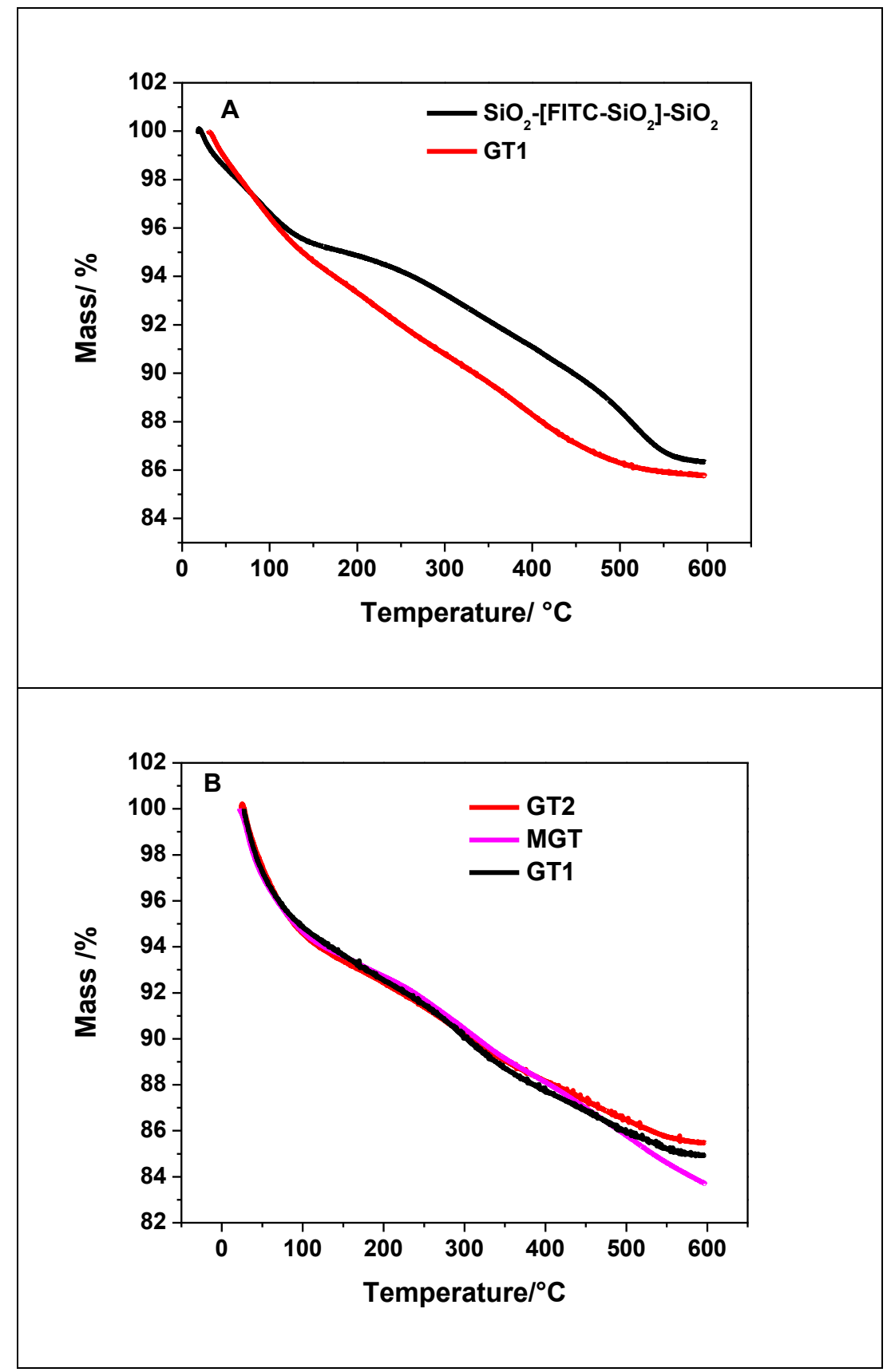

Figure S3.11. TG traces of the pristine silica and PSLGc-1 (A) and comparative TGA traces of all three grafting to batches of PSLG hybrids (B). 
Colloidal Cholesteric Liquid Crystals, CCLCs:

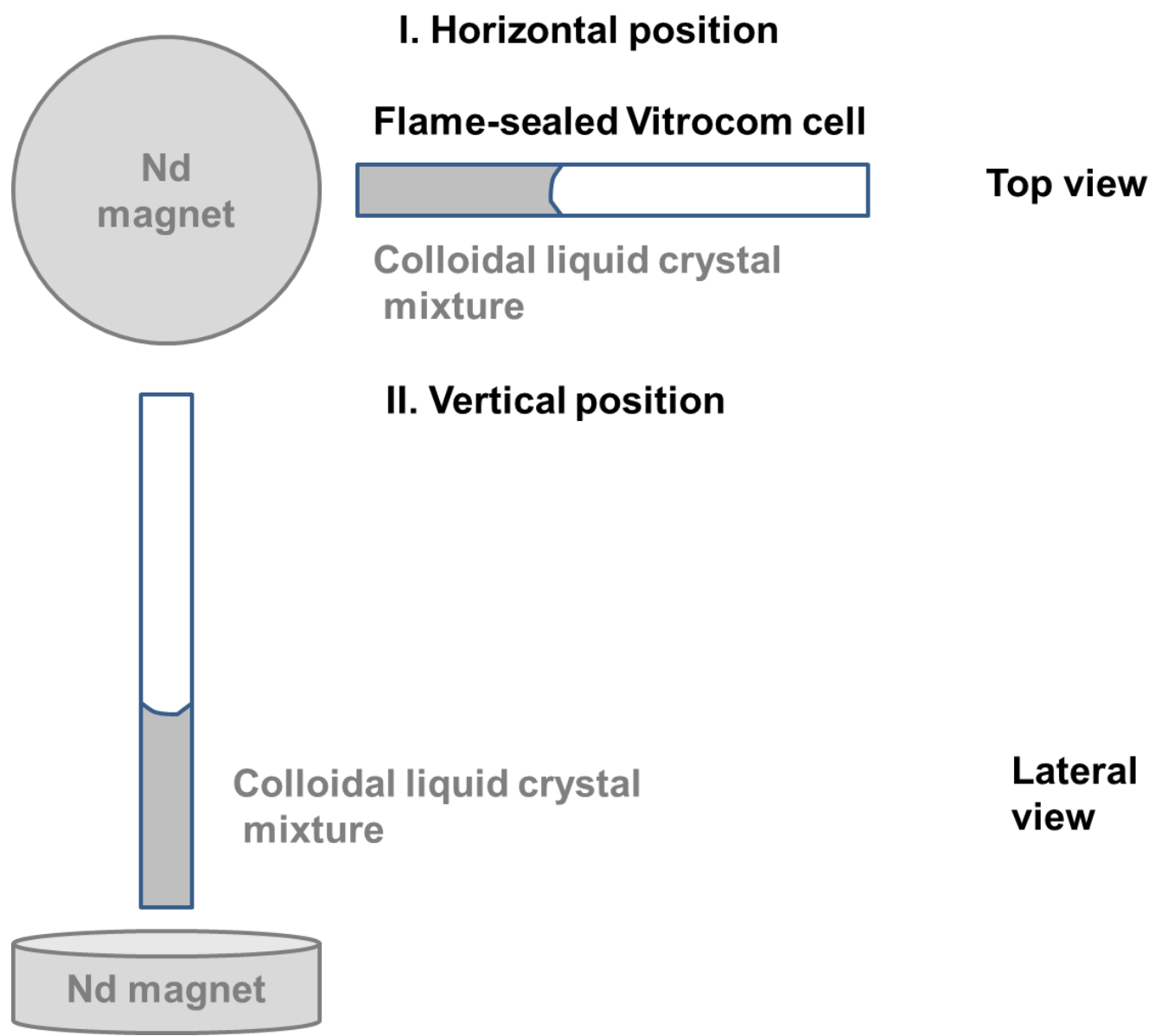

Figure S3.12. Schematic illustration of the two positions used to keep the Vitrocom-cell during exposure to an external magnetic field. 


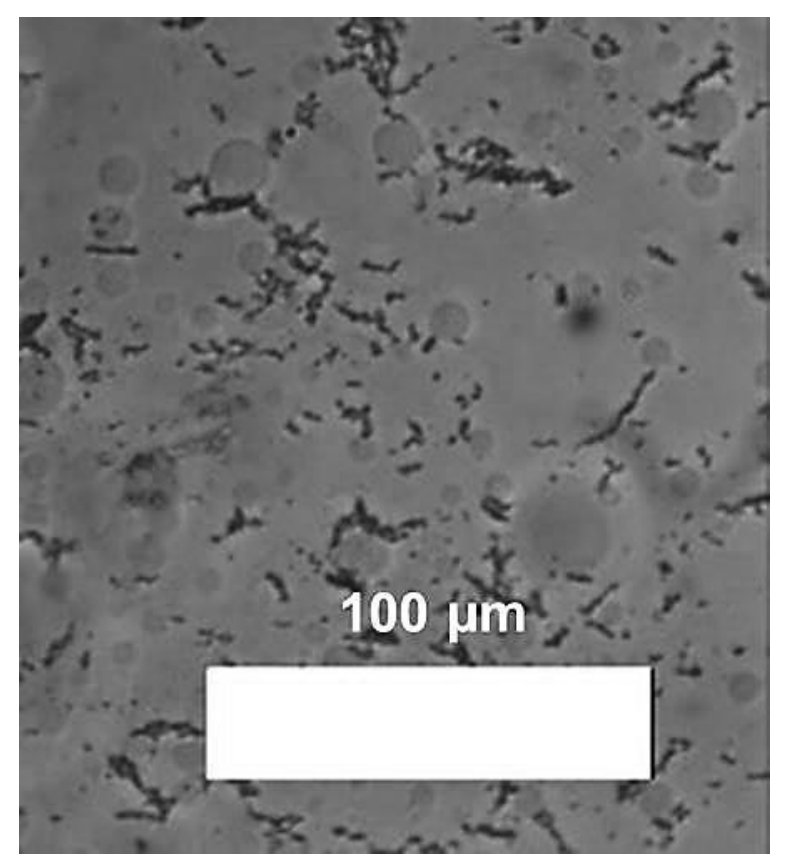

Figure S3.13. Optical micrograph (no crossed polarizers) after 2 months of small colloidal pearl-like strings observed in non-cholesteric LC areas of $5 \mathrm{wt} \%$ MGT/CLC. Vitrocom cell in vertical position. Scale bar $100 \mu \mathrm{m}$.

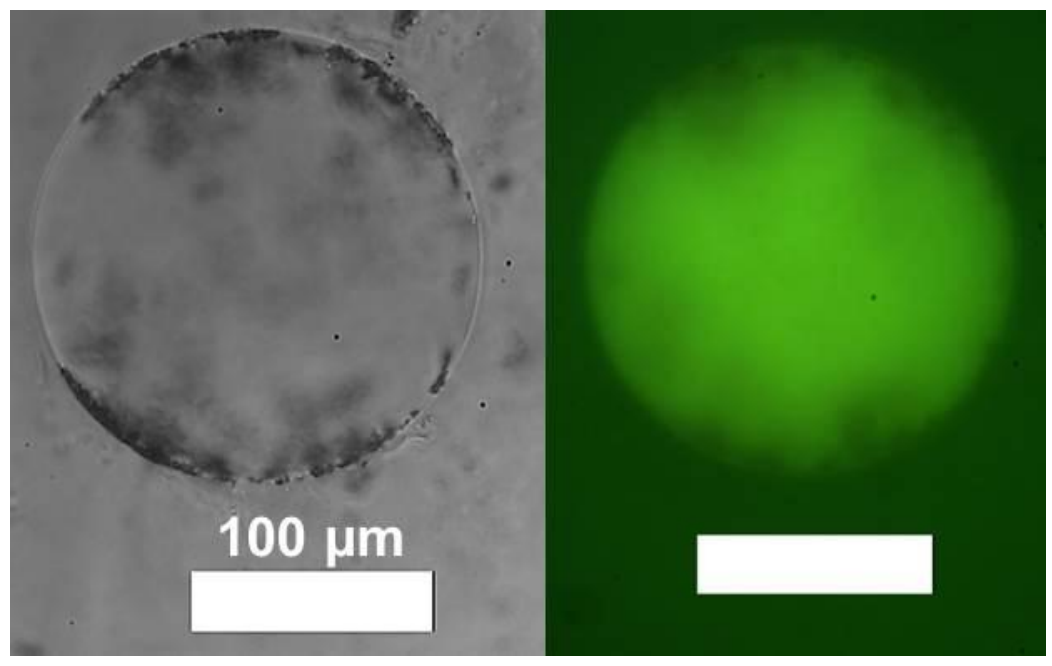

Figure S3.14. Higher magnification optical micrograph of a MGT islet (A) no crossed polarizers and (B) fluorescence image. Scale bar $100 \mu \mathrm{m}$. 


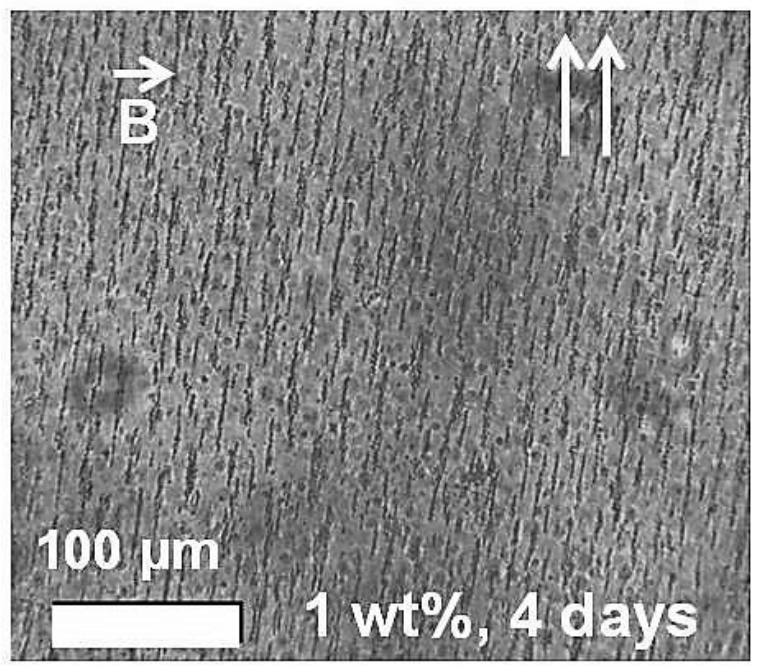

Figure S3.15. Optical micrographs of $1 \mathrm{wt} \%$ MGT hybrid particles suspended in $40 \%$ PSLG $\left(M_{\mathrm{w}}=60,000 \mathrm{Da}\right) /$ toluene after 4 days showing fast response to the magnet position change. The reader is invited to compare this figure with Figure $11 \mathrm{~B}$ in the main text.

\section{Section S4. Calculation of Average Helix Orientation, $\theta$ (tilt angle) for MGT and MGF1 composite particles}

The average angle between the helices was calculated from the FTIR transmission spectra. The tilt angle, $\theta$, (Figure S4-1) was computed using the expression of Miura et al. ${ }^{26}$ : 


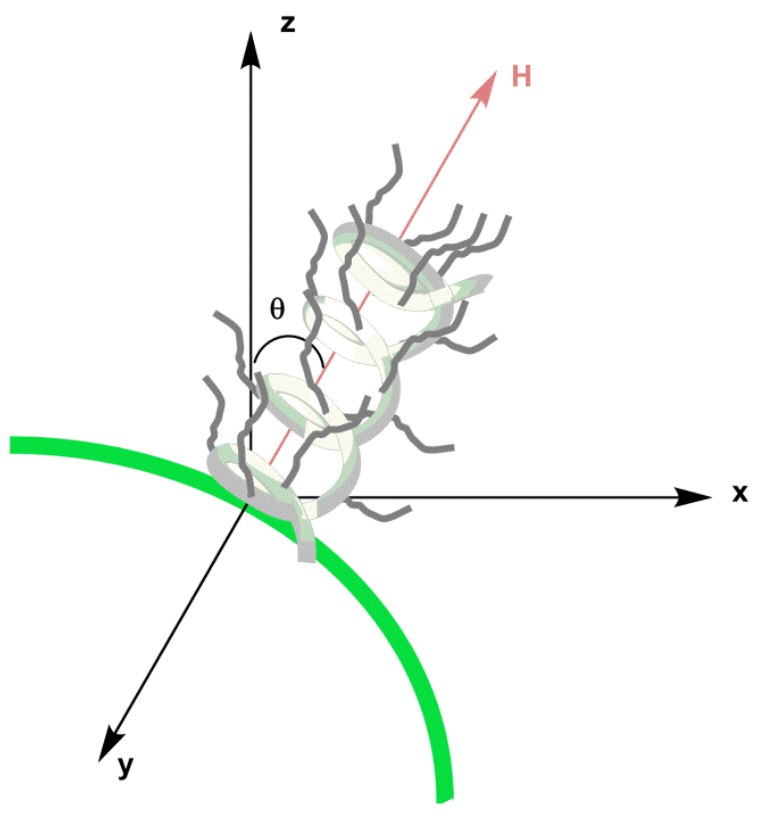

Figure S.4.1. Schematic illustration of $\alpha$-helix arrangement.

For these calculations, the interactions between the transition dipole moments were neglected. The $\theta_{\mathrm{I}}$ and $\theta_{\mathrm{II}}$ values were published in the literature. ${ }^{27}$ The scaling constant was calculated from the ratio of the amide I and amide II peak intensities of the untethered alkyne end-terminated PSLG. The value found was $1.54 \pm 0.2$ which agrees with the literature reports. ${ }^{27}$ The calculations for MGF1 followed the same steps. All parameters involved in these calculations are summarized in Table S4-1.

Table S4-1. Parameters Used in Average-tilt Angle calculations and the Results for the Corresponding Samples

\begin{tabular}{|c|c|c|c|c|c|c|}
\hline \multirow[t]{2}{*}{ Sample } & \multicolumn{2}{|c|}{ Peak height* } & \multicolumn{2}{|c|}{$\begin{array}{c}\text { Transition dipole moment } \\
\text { direction/deg. }\end{array}$} & \multirow[t]{2}{*}{$D_{\text {obs }}$} & \multirow{2}{*}{$\begin{array}{c}\text { Average- } \\
\text { helix } \\
\text { orientation } \\
\text { angle, } \theta / \text { deg }\end{array}$} \\
\hline & $\begin{array}{c}\text { Amide } \\
\text { I }\end{array}$ & $\begin{array}{c}\text { Amide } \\
\text { II }\end{array}$ & $\overline{\theta_{\mathrm{I}}}$ & $\theta_{\mathrm{II}}$ & & \\
\hline MGT & 1.85 & 1.2 & 39 & 75 & $1.54 \pm 0.2$ & $50 \pm 2.5$ \\
\hline MGF1 & 1.5 & 1.9 & 39 & 75 & 1.96 & $51 \pm 2$ \\
\hline
\end{tabular}




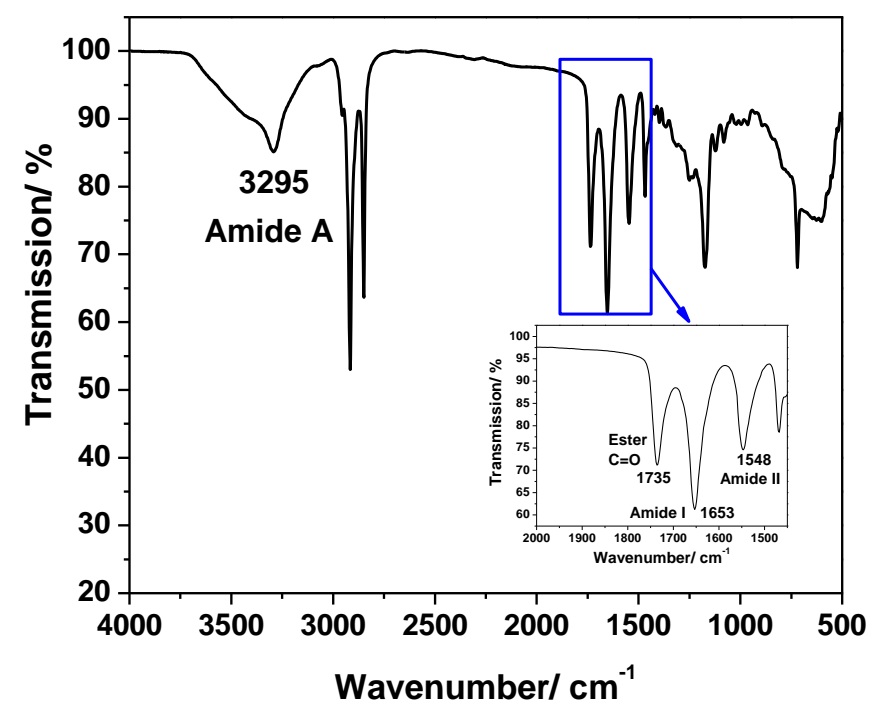

Figure S4.2. FTIR spectrum of untethered PSLG.

\section{Section S5. Calculation of Polypeptide Grafting Density}

These calculations follow the line of the work published by Balamurugan et al. ${ }^{12}$

Let us define $w^{\mathrm{H}}$ as the weight loss from a $1 \mathrm{~g}$ sample of the hybrid particles MGT (i.e., the fractional weight loss that occurs between $200^{\circ}-600^{\circ} \mathrm{C}$ ). The untethered polypeptide TGA trace (Figure S5.2) shows that the shell does not burn to zero ashes. Therefore a correction factor needs to be considered. Let $f_{\mathrm{PSLG}}$ be the fraction of shell polymer that burns off $(0<\mathrm{f}<1)$ where $f$ is measured separately on the pure shell polymer (no cores). Thus the shell mass in a $1 \mathrm{~g}$ composite sample is:

$$
f_{P S L G}^{-1} w^{H}
$$

The core mass is:

$$
1-f_{P S L G}^{-1} w^{H}
$$

Further, let's consider the water loss of the silica core, $w_{\text {silica, }}$ as fractional weight loss from pure silica core particles (no shell) measured separately without regard for the $200^{\circ}-600^{\circ} \mathrm{C}$ limit. This amount, $w_{\text {silica, }}$, is typically no larger than $10 \%$ and accounts for absorbed water, $\mathrm{H}-$ 
bonded water and hydroxyl groups. Some of the mass lost when heating the hybrid composite particle is really from the core. This quantity can be estimated by multiplying the mass of silica core by the water/OH contribution (percentage).

Consequently, the weight loss from a $1 \mathrm{~g}$ hybrid sample that is due to the core losing water/OH is:

$$
\left(1-f_{P S L G}^{-1} w^{H}\right) \times w_{\text {silica }} \quad \text { S5-C }
$$

Then the true weight lost from the shell is:

$$
f_{P S L G}^{-1} w^{H}-\left(1-f_{P S L G}^{-1} w^{H}\right) \times w_{\text {silica }} \quad \text { S5-D }
$$

The total area of the silica core surface is the product between the core mass and specific surface area:

$$
A=\left(1-f_{P S L G}^{-1} w^{H}\right) \times S_{\text {spec }} \quad \text { S5-E }
$$

The grams of shell lost per area of surface are:

$$
\frac{f_{P S L G}^{-1} w^{H}-\left(1-f_{P S L G}^{-1} w^{H}\right) \times w_{\text {silica }}}{\left(1-f_{P S L G}^{-1} w^{H}\right) \times S_{\text {spec }}} \quad S 5-\mathrm{F}
$$

To express the grafting density in moles $\cdot \mathrm{m}^{-2}$, Eq. S5-F will be divided then by the molecular weight of PSLG, $M$ :

$$
\sigma^{P S}=\frac{f_{P S L G}^{-1} w^{H}-\left(1-f_{P S L G}^{-1} w^{H}\right) \times w_{\text {silica }}}{M \times\left(1-f_{P S L G}^{-1} w^{H}\right) \times S_{\text {spec }}} \quad S 5-G
$$

Usually the expression S5-G is multiplied by $10^{6}$ to arrive at the $\mu \mathrm{mol} \cdot \mathrm{m}^{-2}$ unit:

$$
\sigma^{P S}=\frac{f_{P S L G}^{-1} w^{H}-\left(1-f_{P S L G}^{-1} w^{H}\right) \times w_{\text {silica }}}{M \times\left(1-f_{P S L G}^{-1} w^{H}\right) \times S_{\text {spec }}} \times 10^{6} \quad S 5-\mathrm{H}
$$

Below is a snapshot of the Excel spreadsheet used to calculate the polypeptide grafting density of the MGT hybrid. 


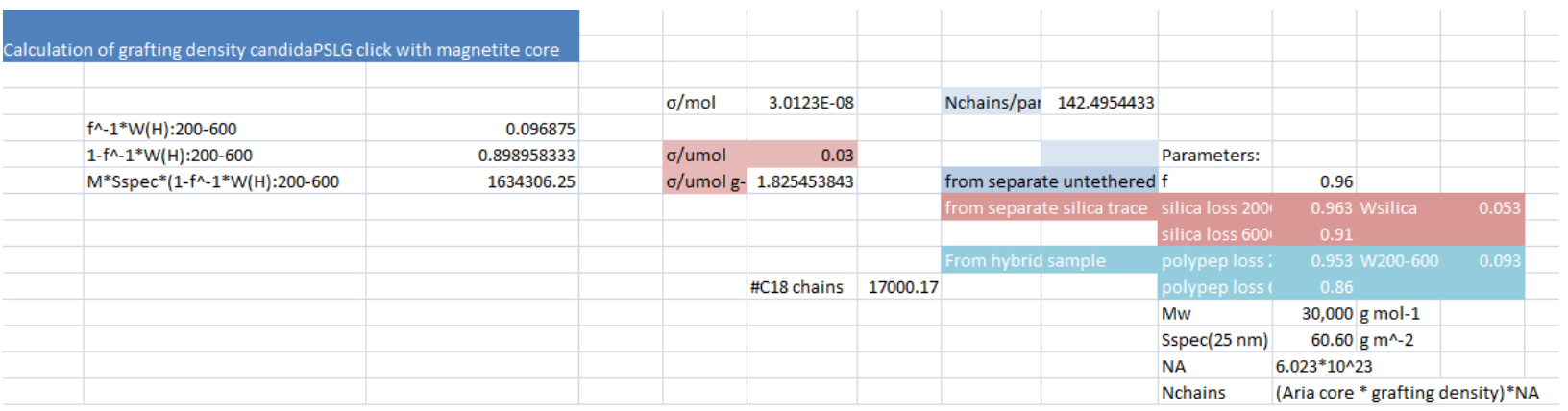

Figure S5.1. Excel spreadsheet showing an example of the polypeptide grafting density calculations.

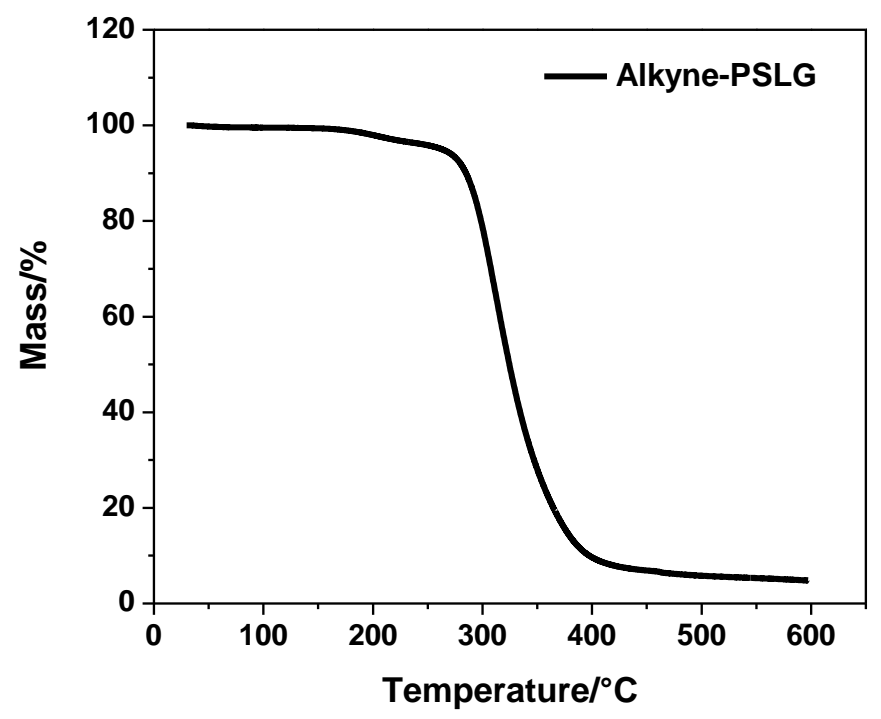

Figure S5.2. TGA response of untethered alkyne-PSLG. 


\section{References}

1. Massart, R., preparation of aqueous magnetic liquids in alkaline and acidic media. IEEE trans. Magn. 1981, 17 (2), 1247-1248.

2. $\quad$ Philipse, A. P.; Vanbruggen, M. P. B.; Pathmamanoharan, C., magnetic silica dispersions - preparation and stability of surface-modified silica particles with a magnetic core. Langmuir 1994, 10 (1), 92-99.

3. Yang, D.; Hu, J. H.; Fu, S. K., Controlled Synthesis of Magnetite-Silica Nanocomposites via a Seeded Sol-Gel Approach. J. Phys. Chem. C 2009, 113 (18), 7646-7651.

4. Bogush, G. H.; Tracy, M. A.; Zukoski, C. F., Preparation of monodisperse silica particles - control of size and mass fraction. J. Non-Cryst. Solids 1988, 104 (1), 95-106.

5. Deng, Y. H.; Wang, C. C.; Hu, J. H.; Yang, W. L.; Fu, S. K., Investigation of formation of silica-coated magnetite nanoparticles via sol-gel approach. Collois Surf., A 2005, 262 (1-3), 87-93.

6. Ma, Z.; Guan, Y.; Liu, H., Superparamagnetic silica nanoparticles with immobilized metal affinity ligands for protein adsorption. J. Magn. Magn. Mater. 2006, 301 (2), 469477.

7. Salgueiriño-Maceira, V.; Correa-Duarte, M. A.; Spasova, M.; Liz-Marzán, L. M.; Farle, M., Composite Silica Spheres with Magnetic and Luminescent Functionalities. Adv. Funct. Mater. 2006, 16 (10), 1266-1266.

8. Stober, W.; Fink, A.; Bohn, E., Controlled Growth of Monodisperse Silica Spheres in the Micron Size Range. J. Colloid Interface Sci. 1968, 26, 62-69.

9. Zhang, J. H.; Zhan, P.; Wang, Z. L.; Zhang, W. Y.; Ming, N. B., Preparation of monodisperse silica particles with controllable size and shape. J. Mater. Res. 2003, 18 (3), 649-653.

10. Lee, M. H.; Beyer, F. L.; Furst, E. M., Synthesis of monodisperse fluorescent core-shell silica particles using a modified Stober method for imaging individual particles in dense colloidal suspensions. J. Colloid Interface Sci. 2005, 288 (1), 114-123.

11. Van Blaaderen, A.; Vrij, A., Synthesis and characterization of colloidal dispersions of fluorescent, monodisperse silica spheres. Langmuir 1992, 8 (12), 2921-2931.

12. Balamurugan, S. S.; Soto-Cantu, E.; Cueto, R.; Russo, P. S., Preparation of Organosoluble Silica-Polypeptide Particles by "Click" Chemistry. Macromolecules 2010, $43(1), 62-70$. 
13. Ranjan, R.; Brittain, W. J., Tandem RAFT polymerization and click chemistry: An efficient approach to surface modification. Macromol. Rapid Commun. 2007, 28 (21), 2084-2089.

14. Ranjan, R.; Brittain, W. J., Combination of living radical polymerization and click chemistry for surface modification. Macromolecules 2007, 40 (17), 6217-6223.

15. Ranjan, R.; Brittain, W. J., Synthesis of high density polymer brushes on nanoparticles by combined RAFT polymerization and click chemistry. Macromol. Rapid Commun. 2008, 29 (12-13), 1104-1110.

16. Zhao, L.; Zhao, Y. F.; Han, Y., Pore Fabrication in Various Silica-Based Nanoparticles by Controlled Etching. Langmuir 2010, 26 (14), 11784-11789.

17. Wasserman, D., Garber, J. D. and Meigs, F. M. U.S. 3285 953, 1966.

18. Daly, W. H.; Poché, D., The preparation of N-carboxyanhydrides of $\hat{\mathrm{I}} \pm$-amino acids using bis(trichloromethyl)carbonate. Tetrahedron Lett. 1988, 29 (46), 5859-5862.

19. Deng, Y. H.; Yang, W. L.; Wang, C. C.; Fu, S. K., A novel approach for preparation of thermoresponsive polymer magnetic microspheres with core-shell structure. Adv. Mater. 2003, 15 (20), 1729-+.

20. Fong, B.; Russo, P. S., Organophilic colloidal particles with a synthetic polypeptide coating. Langmuir 1999, 15 (13), 4421-4426.

21. Collman, J. P.; Devaraj, N. K.; Eberspacher, T. P. A.; Chidsey, C. E. D., Mixed azideterminated monolayers: A platform for modifying electrode surfaces. Langmuir 2006, 22 (6), 2457-2464.

22. Wollman, E. W.; Kang, D.; Frisbie, C. D.; Lorkovic, I. M.; Wrighton, M. S., Photosensitive self-assembled monolayers on gold - photochemistry of surface-confined aryl azide and cyclopentadienylmanganese tricarbonyl. J. Am. Chem. Soc. 1994, 116 (10), 4395-4404.

23. Schrupp, D.; Sing, M.; Tsunekawa, M.; Fujiwara, H.; Kasai, S.; Sekiyama, A.; Suga, S.; Muro, T.; Brabers, V. A. M.; Claessen, R., Surface electronic structure and Verweytransition of magnetite studied by photoemission spectroscopy. Annalen Der Physik 2004, 13 (1-2), 78-80.

24. Zhang, L.; He, R.; Gu, H. C., Oleic acid coating on the monodisperse magnetite nanoparticles. Applied Surface Science 2006, 253 (5), 2611-2617.

25. Morel, A. L.; Nikitenko, S. I.; Gionnet, K.; Wattiaux, A.; Lai-Kee-Him, J.; Labrugere, C.; Chevalier, B.; Deleris, G.; Petibois, C.; Brisson, A.; Simonoff, M., Sonochemical 
approach to the synthesis of $\mathrm{Fe}_{3} \mathrm{O}_{4} @ \mathrm{SiO}_{2}$ core-shell nanoparticles with tunable properties. ACS Nano 2008, 2 (5), 847-856.

26. Miura, Y.; Kimura, S.; Imanishi, Y.; Umemura, J., Formation of Oriented Helical Peptide Layers on a Gold Surface Due to the Self-Assembling Properties of Peptides. Langmuir 1998, 14 (24), 6935-6940.

27. Wieringa, R. H.; Siesling, E. A.; Werkman, P. J.; Angerman, H. J.; Vorenkamp, E. J.; Schouten, A. J., Surface grafting of poly(L-glutamates). 2. Helix orientation. Langmuir 2001, 17 (21), 6485-6490. 